SLA-73-0912

Unlimited Release

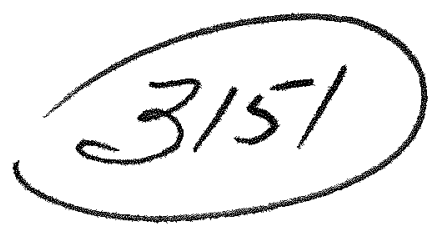

\title{
Development of the
}

Glass Bonding Process for the MC2730 Thermopile

E. K. Beauchamp, J. Matsko

1. 1.

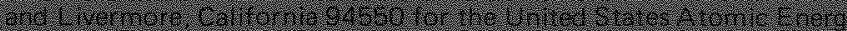

6.

t.

Sandia Laboratories 


\section{DISCLAIMER}

This report was prepared as an account of work sponsored by an agency of the United States Government. Neither the United States Government nor any agency Thereof, nor any of their employees, makes any warranty, express or implied, or assumes any legal liability or responsibility for the accuracy, completeness, or usefulness of any information, apparatus, product, or process disclosed, or represents that its use would not infringe privately owned rights. Reference herein to any specific commercial product, process, or service by trade name, trademark, manufacturer, or otherwise does not necessarily constitute or imply its endorsement, recommendation, or favoring by the United States Government or any agency thereof. The views and opinions of authors expressed herein do not necessarily state or reflect those of the United States Government or any agency thereof. 


\section{DISCLAIMER}

Portions of this document may be illegible in electronic image products. Images are produced from the best available original document. 
Issued by Sandia Laboratories, operated for the United States Atomic Enetgy Commission by Sandia Corporation.

\section{NOTICE}

This report was prepared as an account of work sponsored by the United States Government. Neither the United States nor the United States Atomic Energy Commission, nor any of their employees, nor any of their contractors, subcontractors, or their employees, makes any warranty, express or implied, or assumes any legal liability or responsibility for the accuracy. completeness or usefulness of any information, apparatus, product or process disclosed, or represents that its use would not infringe privately owned rights. 
SIA-73-0912

DEVELOPMENT OF THE GLASS BONDING

PROCESS FOR THE MC2730 THERMOPIIE

E. K. Beauchamp, 5846

and.

J. Matsko, 3622-1

September, 1974

ABSTRACT

This repont was prepared as an account of work sponsored by the United States Government. Neither the United States nor the United States Atomic Energy Commission, nor any of ther employees, nor any of they contractors, subcontractors, or their employees, makes any warranty, express or amplied, or assumes any legal liability or tesponsibitity for the accuracy, completeness or usefuness of any information, apparatus, product of process disclosed, or represents that its use would not infringe privately owned rights.

Techniques for bonding the 44 elements of the MC2730 thermopile into a rigid, strong assembly have been developed. The requirement for a nearly pore-free bond to serve as a bridge for interelement contact metallizing has been met by using a thin layer of glass frit and vacuum hot pressing to virtually eliminate porosity. The bonding glass has been identified as a source for gases which produce porosity and procedures have been developed to prevent the release of the gases. Precise control over bond thickness has been obtained through improvements in screen printing and tape deposition processes and by elaborate fixturing during bonding. 
I. Introduction

Page

II. Design Constraints

A. Bond Requirements 6

B. Material Selection 9

III. Preliminary Development 11

A. Glassing Experiments 11

B. Preliminary Pile Bonding Experiments 14

IV. The Bonding Process 19

A. Preliminary Procedures 21

B. Vacuum Hot Pressing 29

V. Wafer Stack and Thermopile Defects 33

A. Thermopile Element Misalignment 34

B. Voids 36

C. Shorts 38

References $\quad 44$

Appendix A 45

Acknowledgments $\quad 50$ 
Figure 1 RTG AssembIy 4

Figure 2 MC2730 Thermopile Assembly 5

Figure 3 2-D Thermoelement Configuration 6

Figure 4 End Face of 1-D Thermopile Assembly Showing 8 Tungsten Pads

Fisure 5 Viscosity Versus Temperature Curves for Various 10 Glasses

Figure $6 \quad$ Photograph of 2-D Thermopile 16

Figure 7 Defects in 2 D Thermopile 16

Figure 8 Thermopile Bonded with 0.004 Inch Thick Sheet 18 Glass (End Face). IOX Mag。

Figure 9 Flow Diagram for 1-D Bonding Process 20

Figure 10 "Haze" Layer in the Bond Interface. I25X Mag. 22

Figure 11 Photograph of Screen Printer 25

Figure 12 Assembled Wafer Stack and Fixture 29

Figure 13 Iower Spacer-Thermopile-Fixture AssembIy 30

Figure 14 Hot Pressing Cycle for Stack Bonding 31

Figure 15 Hot Pressing Cycle for Pile Bonding 31

Figure 16 Interelement Alignment Defects 35

Figure 17 Voids in the Glass Bond 37

Figure 18 "Breakout" at the Bond Interface 37

Figure 19 Conductive "MetaI" Marking Produced in Sawing. 39 200X Mag. IIST OF TABLES

Table I Glass Properties 12

Table II First Bond Resistance Data 43 


\section{INTRODUCTION}

The MC2730 Radioisotopic Thermoelectric Generator (RTG) consists basically of a heat source (a fuel capsule containing plutonium oxide) and a pair of thermopile channels. ${ }^{1}$ The heat source and thermopile assembly are coupled mechanically and sealed in an insulated can as shown in Fig. 1.

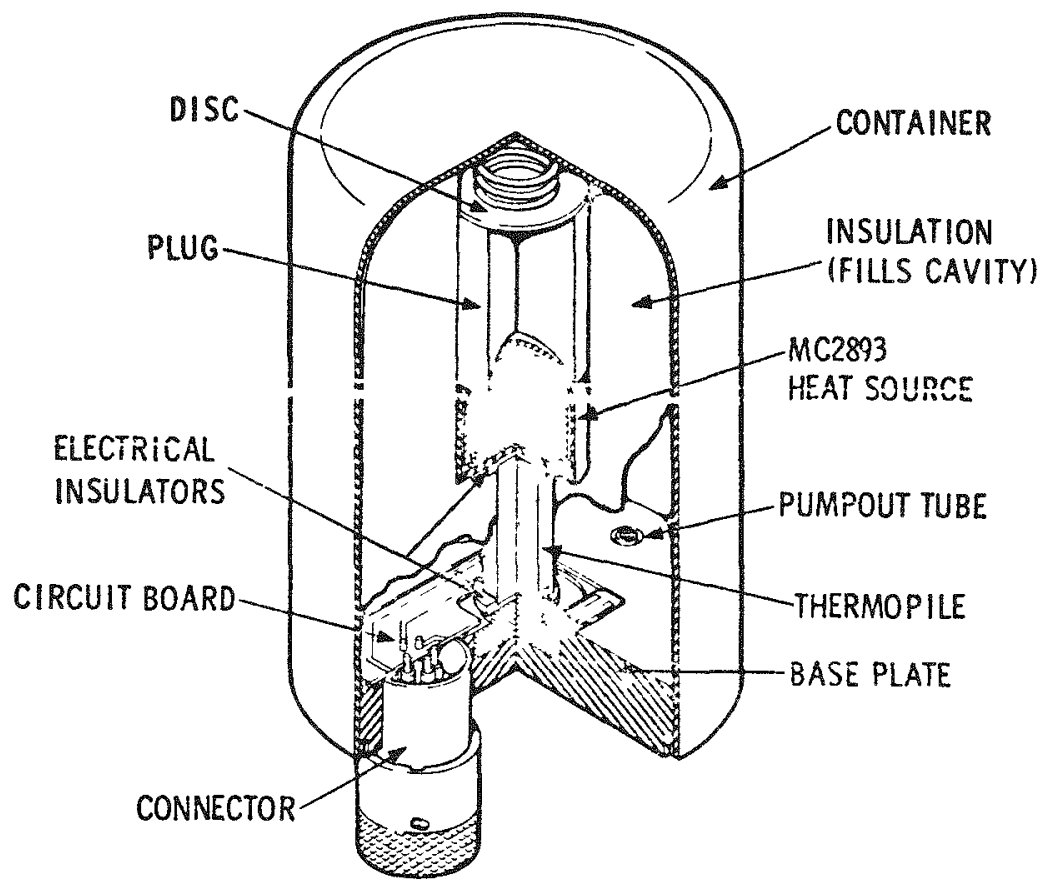

Fig. I RIG Assembly

The RTG is intended to provide a minimum power output of $25 \mathrm{~mW}$ per thermopile channel at two volts for a service life of eight years. To produce that power, the thermopile is maintained in a thermal gradient with a maximum hot junction temperature of $450^{\circ} \mathrm{C}$. In the I-D tungsten-contact thermopile design, the thermopile consists of 22 couples of alternating $p$ - and $n$-doped silicon-germanium (Si-Ge) elements interconnected with tungsten.

Although a substantial thermoelectric generator technology has been developed for space applications, there are aspects of the MC2730 which make it unique. The most exceptional aspect is the physical size of the thermo- 
electric elements. Generally, thermoelectric elenents in space power applications are relatively large ( $\frac{1}{6}$ to $\frac{1}{3}$ Inch diameter) with a low length-todiameter ratio. With elements this large, thermal and electrical conneca tions are commonily mde by brazing or solid-state diffusion or, as in SNAP27, through mechanical spring loading of individual elements. However, in the MC2730, the individual elements of the thermopiles have aimensions of 0.007 inch $\times 0.140$ inch $\times 1.000$ inch. The brittle mechanical behavior of the Si-Ge alloys makes these thin elements too fragile to be handled individually in the generator assembly. Instead, the elements are bonded into a structure (Fig. 2) prior to making electrical connections and the rmal contacts. This paper describes the development of the bonding processes used in assembing this structure.

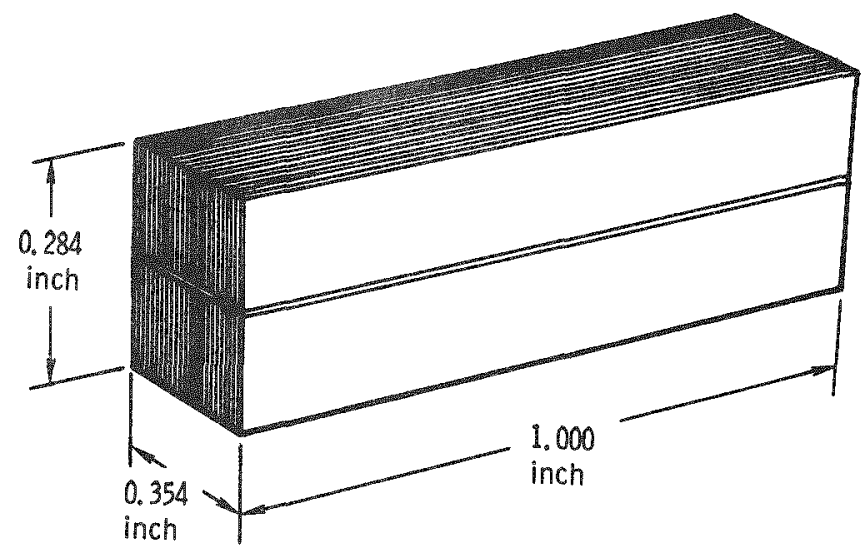

Fig. 2 MC2730 Thermopile Assembly

The development of the I-D tungsten-contact thermopile is the culmination of a program which had the initial goal of producing a 2-D bonded thermopile, 1.e., the assembly shown in Fig. 3. ${ }^{*}$ The 2-D thermopile development will not be described in detail in this report. Only those aspects of the 2-D program which substantially influenced the 1-D development will be described (Section III).

\footnotetext{
* The designation 2-D indicates that there are bonds in two directions within a thermopile channel. The 1-D thermopile is bonded in only one direction. (There is a second bond in the I-D themopile assembly, but it is between two thermopile channels.)
} 


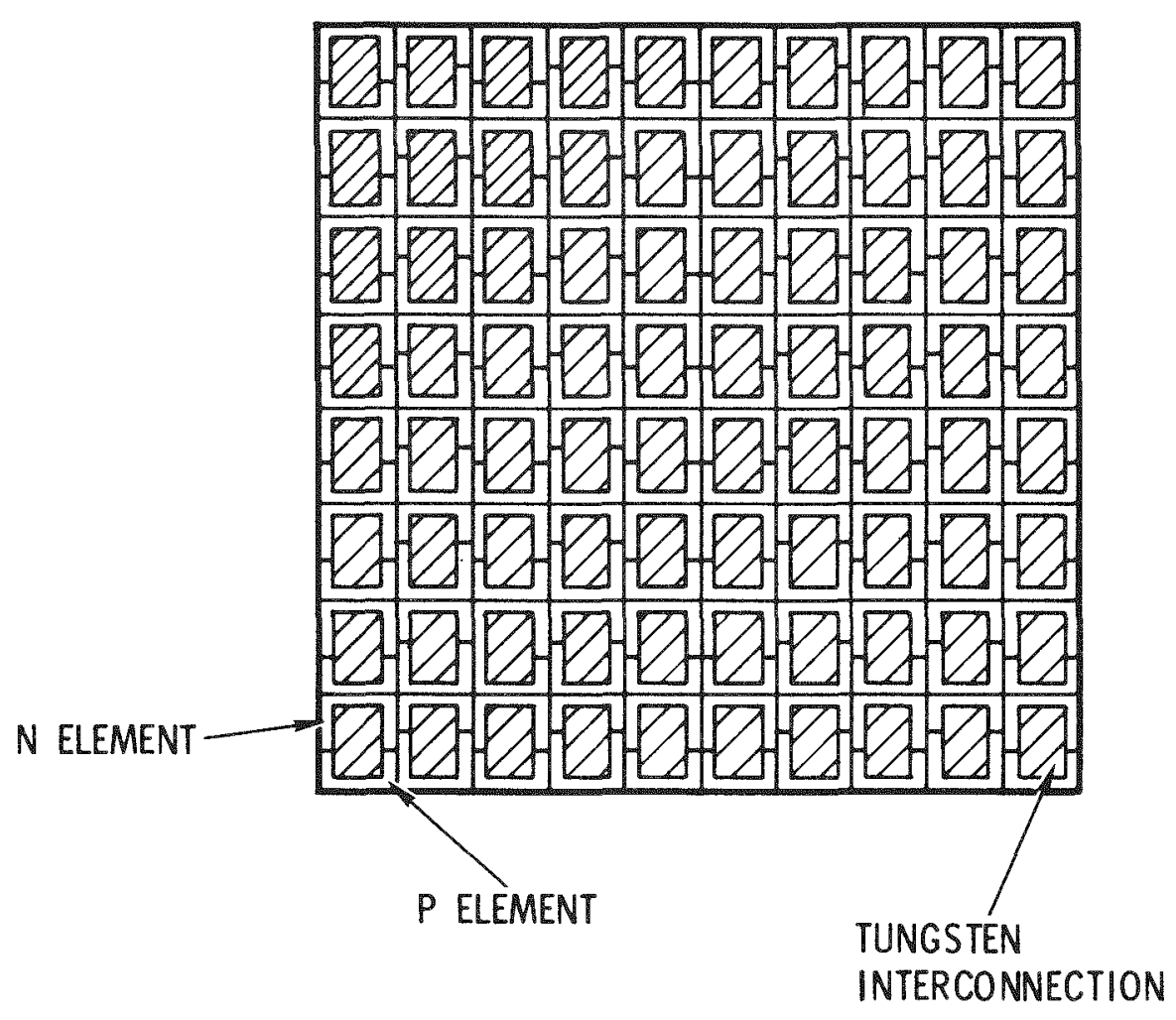

Fig. 3 2-D Thermoelement Configuration

\section{DESIGN CONSTRAINTS}

\section{A. Bond Requirements}

Basically, the bond must provide mechanical support to the structure without adversely affecting the performance of the thermopile. The bonding material must, therefore, be electrically insulating at the operating temperatures. It must be chemically compatible with the Si-Ge and the tungsten contacts, i.e., the thermoelectric performance of the si-Ge must not be degraded by diffusion of contaminants through the bond interface and the integrity of the tungsten contact must be maintained.

Additional requirements are placed on the bonding material by the need for efficient use of the fuel in the capsule. Excessive thermal loss through the bond would raise the thermal power requirements, i.e., the fuel loading. It is, therefore, essential that the bond material have low thermal conducductivity and/or that the bond layer be thin compared with the Si-Ge elements. 
Another constraint on the design is imposed by the large temperature excursions which the themopile assembly experiences before it is finally incorporated into the generator. The first large excursions are associated with the bonding processes themselves. Somewhat smaller excursions occur during the interconnection process and in the final attachment to the heat source. To prevent the development of excessive stresses during these excursions (and, thus, to protect the fragile si-Ge elements), the expansion coefficient of the bonding material should match that of the Si-Ge reasonably we11. Any mismatch should be in a direction that puts the elements in compression and the bond in tension since a crack in the bond could be tolerated while one through an element could not.

Two of the major constraints on the nature of the bond result from the scheme used to produce electrical connections between elements. These contacts are made with a thin film of tungsten which is sputtered over the entire end face of the thermopile assembly after the bonding process is completed. SubsequentIy, the contacts between the elements are defined by photolithography and the excess tungsten is etched away. The layout of the tungsten pads on the hot junction end of the thermopile is shown in Fig. 4. One of the constraints placed by the use of tungsten is on the dimensional control of the bond. Because the contact resistance between tungsten and Si-Ge is high, it is essential to provide as large a contact area as possible. As is apparent in Fig. 4, the contact area is a large fraction of the element end surface. It is desirable to locate these contact pads within 0.001 inch of their prescribed location. A calculation based on a statistical addition of tolexances indicates that to index a photolithographic mask with every element in a pile within the desired 0.001 inch, both the bond thicknesses and the element thicknesses would have to be con- 


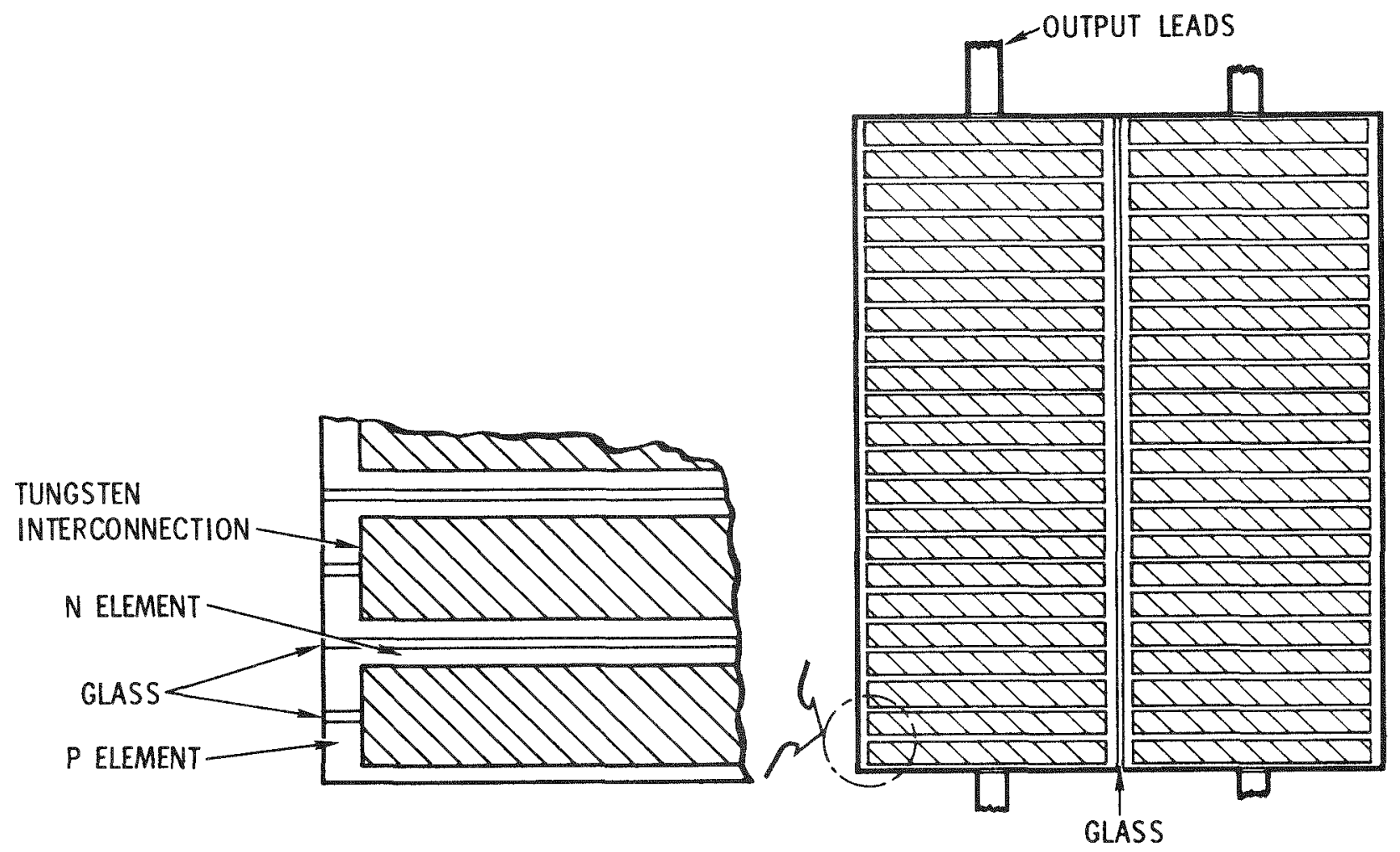

Fig. 4 End Face of I-D Thermopile Assembly Showing Tungsten Pads

trolled to within $25 \times 10^{-6}$ inches of the nominal values. There appears to be no practical way to achieve this kind of control. Nevertheless, a substantial saving in the time necessary for the photolithography can be gained by providing sufficient control to permit the use of a mask covering six to twelve elements rather than just a pair of elements. One of the program objectives was, therefore, controlling the bond and element thicknesses to the 0.0001 inch required for these masks.

The second constraint imposed by the use of tungsten film contacts is on the quality of the bond surface in the contact area. The bond material forms the bridge supporting the tungsten film between the contacts. In the situation where a large part of that bridge area is missing, because of substantial porosity in the bond, for example, the resistance of the connection will be raised and the electrical output of the generator will be affected. Even at a very low level of porosity, pores can effect the performance of 
the RTG. Tungsten sputtered into a pore which extends across the bond rem gion cannot always be removed in the etching process. The result can be an unwanted electrical contact between the elements which effectively shorts out one thermocouple. Thus, it is essential to maintain a very low level of porosity in the bonds.

\section{B. Material Selection}

Although there are crystalline inorganic insulating materials which might have been melted to form a bond at temperatures between $450^{\circ} \mathrm{C}$ and the melting point of the Si-Ge alloy $\left(1280^{\circ} \mathrm{C}\right)$, their expansion coefficients are generally much higher than that of $\mathrm{Si}-\mathrm{Ge}$ and no serious consideration was made toward using them. The $450^{\circ} \mathrm{C}$ maximum hot junction temperature precluded the use of organics, including the polyimides. The only class of materials which appeared to have the desired properties for bonding were the inorganic glasses.

There are a number of commercially available silicate glasses which satisfy the basic requirements for bonding. In general, silicate glasses have low thermal conductivity. They also, generally, have low electrical conductivity at room temperature. They are, however, ionic conductors and their conductivity increases with temperature. Fortunately, at $450^{\circ} \mathrm{C}$, they still can be used in the thermopile without electrical problems.

The requirement of an approximate thermal expansion $(\alpha)$ match to the SiGe restricts the selection of glasses to those with $\alpha$ between 4 and $5 \times 10^{-6}$ per degree $C$. Many of the commercial glasses in this range had been developed for sealing to tungsten, which has an expansion close to that of si-Ge.

A further restriction on the selection of a glass for bonding is imposed by the requirement that the bond must be mechanically stable at $450^{\circ} \mathrm{C}$, i.e., it must not deform enough to rupture the tungsten contacts or permit 
mechanical failure of the structure. There is also an upper limit to the temperature at which the bond can be formed. At the inception of this prom gram, the upper limit was considered to be the melting point of the Si-Ge $\left(1280^{\circ} \mathrm{C}\right)$. As will be discussed in a later section, the glasses finally selected for bonding tend to liberate dissolved gases and form bubbles at temperatures above $900^{\circ} \mathrm{C}$ and so bonding is performed below that temperature.

If glasses behaved like most crystalline materials with a well-defined melting point below which the material is rigid and above which the viscosity is very low, selection of a bonding material could be made on the basis of a single temperature, the melting temperature. However, as shown in Fig. 5, glasses undergo a gradual viscosity change with temperature. To satisfy the bonding requirements, the viscosity must not only be high enough $\left(\sim 10^{15}\right.$ poise) at $450^{\circ} \mathrm{C}$ to resist deformation, but it must also be low enough ( $<10^{8}$ poise) at temperatures below about $900^{\circ} \mathrm{C}$ to form the bond.

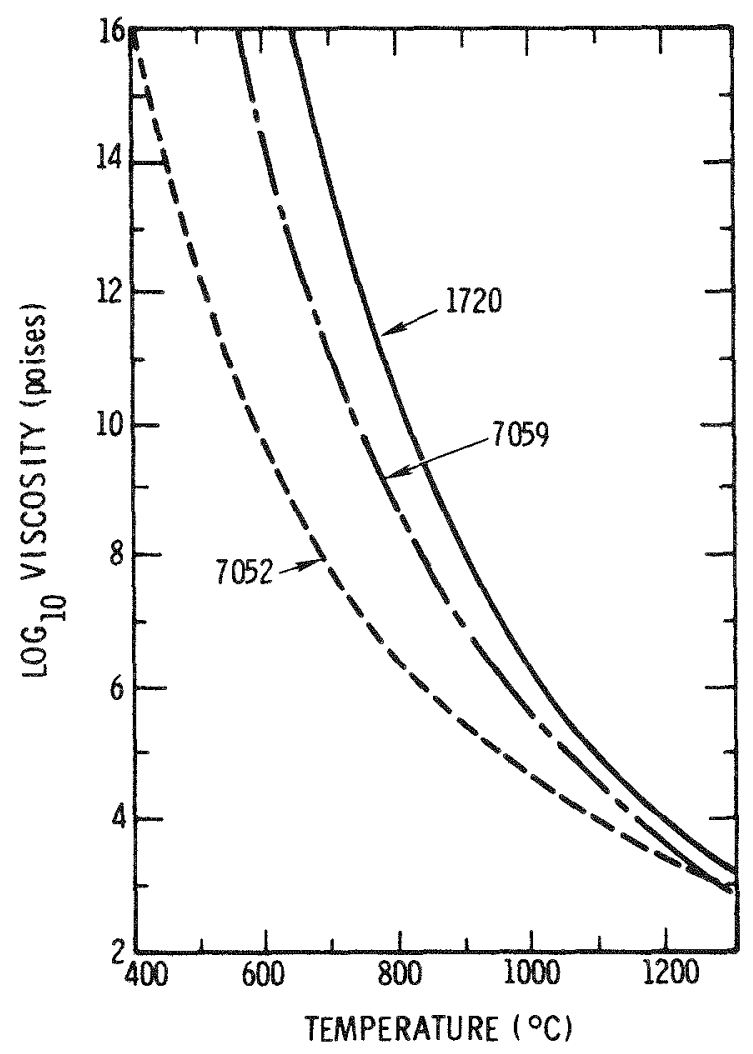

Fig. 5 Viscosity Versus Temperature Curves for Various Glasses 
The selection of bonding materials is further complicated by the assembly of two thermopile channels into a single structure. As will be discussed in the description of the bonding process, the elements are first bonded. into a stack. The stack is then sliced into thermopile channels and a second bonding operation is used to produce the final assembly. To insure against deformation of the first bond and consequent distortion of the pile during the second bonding operation, the viscosity of the first glass should be at least an order of magnitude greatex than that of the second glass at the bonding temperature. The requirement of $10^{15}$ poise viscosity at $450^{\circ} \mathrm{C}$ can be relaxed somewhat for the second bond since there is no electrical connection across that bond.

Table I shows the properties of the glasses which passed the initial screening at the beginning of the program. The first seven of these are made by Corning Glass Works, while the last three are produced by OwensIIIinois. The 0-I EE-2 is essentially the same as CGW's Code 1715 glass. SG-7 has a much lower viscosity than the other glasses, but it can be partially crystallized so that its effective viscosity can be raised above the values shown.

\section{PRELIMINARY DEVEIOPMENT}

\section{A. Glassing Experiments}

The next step in the program, after screening the commercial glasses on the basis of their tabulated properties, was to determine if a suitable bond with Si-Ge could be made and whether the glass Si-Ge reaction would degrade the thermoelectric material. To determine the character of the bonds, powdered glass (frit) of the various compositions was deposited on Si-Ge wafers and the wafers were heated to the working range of the glasses. On 
TABIE I

GLASS PROPERTIES ${ }^{* *}$

\begin{tabular}{|c|c|c|c|c|c|c|c|c|c|c|}
\hline Glass Type & 7052 & 7059 & 1720 & 3320 & 1710 & 1723 & 7061 & $E E-2$ & $\mathrm{KG}-34$ & $S G-7$ \\
\hline \multicolumn{11}{|l|}{ Thermal Expansion } \\
\hline $0-300^{\circ} \mathrm{C}\left(1 \sigma^{-6} /{ }^{\circ} \mathrm{C}\right)$ & 4.6 & 4.7 & 4.2 & 4.0 & 4.2 & 4.6 & 4.45 & 4.3 & 4.3 & 4.1 \\
\hline Working Pt $\left({ }^{\circ} \mathrm{C}\right)$ & & 1160 & 1190 & 1155 & & & 1040 & 1210 & 1200 & $\begin{array}{l}\text { (625 C Firing } \\
\text { Temperature) }\end{array}$ \\
\hline Softening Pt $\left({ }^{\circ} \mathrm{C}\right)$ & & 842 & 915 & 780 & 915 & 910 & 720 & 955 & 810 & 571 \\
\hline Annealing $\mathrm{Pt}\left({ }^{\circ} \mathrm{C}\right)$ & & 635 & 715 & 540 & 720 & 710 & 533 & 761 & 579 & 469 \\
\hline \multicolumn{11}{|c|}{ Composition (wt \% oxides) } \\
\hline $\mathrm{Li}_{2} \mathrm{O}$ & 1.0 & & - & - & & - & & & & \\
\hline $\mathrm{Na}_{2} \mathrm{O}$ & 2.0 & $<2.0$ & 1.0 & 4.0 & & - & $<0.1$ & & & \\
\hline $\mathrm{K}_{2} \mathrm{O}$ & 3.0 & & - & 2.0 & & - & & & & \\
\hline $\mathrm{SiO}_{2}$ & 66.0 & 48.8 & 57.0 & 76.0 & & $57.0^{\prime}$ & & & & \\
\hline $\mathrm{CaO}$ & - & 0.2 & 5.5 & - & & 10.0 & & & & \\
\hline $\mathrm{As}_{2} \mathrm{O}_{3}$ & - & 0.15 & - & - & & - & & & & \\
\hline
\end{tabular}

**Thermodynamic data from manufacturers" sales brochures. Compositions determined by Dept. 5820 analysts. 
subsequent examination of the wafers, it was found that CGW 7061 and $0-I$ EE-2 were opaque, white, and did not completely wet the substrate. 0-I's SG-7 wet well but contained very large crystals, rather than the small ones expected. Both 1720 and 1723 failed to wet the si-Ge surface completely a.lthough they were clear and apparently formed a good bond where wetting occurred. The 7059 glass was somewhat better than 1720 and 1723 but did not wet the substrate completely. The 7052, 3320, and KG-34 glasses gave excellent results.

On the basis of these experiments, 7061 , EE-2, and SG-7 were rejected. Concern over the relatively large amounts of alkali oxides in $\mathrm{KG}-34$ and 3320, and the possible effect on the thermoelectric properties of si-Ge made these glasses risky prospects and their use was deferred. By the time it was conclusively established that alkali ions were no problem, ${ }^{2}$ enough success had been achieved with the other glasses so that these two were not reconsidered.

Of the remaining glasses, only 7059,1720 , and 1723 had sufficiently high viscosity to insure stability of the 2-D thermopile (the initial thermopile design) at the operating temperature. (As indicated earlier, the bond between thermopiles in the 1-D construction did not require a viscosity of $10^{15}$ poise in operation and 7052 was found to be acceptable in that design). Selection of 1720 over the nearly identical 1723 was essentially arbitrary.

At the same time that the glass selection experiments were being performed, some work was done to develop a surface coating for the siGe that would retard diffusion of potential contaminants from the glass into the wafers. Silicon nitride $\left(\mathrm{Si}_{3} \mathrm{~N}_{4}\right)$ appeared to be a reasonable candidate because of its apparent stability and low diffusivity for alkali metals. 3 However, in a series of experiments in which substrates were coated with 
$\mathrm{Si}_{3} \mathrm{~N}_{4}$ using a chemical vapor deposition (CVD) technique, all of the glasses, which were subsequently deposited and melted, literally foamed on the substrate. The conclusion was that in the reaction with the glass the $\mathrm{Si}_{3} \mathrm{~N}_{4}$ had decomposed to release nitrogen gas. Fortunately, as noted earlier, it was determined that the glass did not effect the properties of the sige and the search for a diffusion barrier was abandoned.

\section{B. Preliminary Pile Bonding Experiments}

The first attempts in this program to bond si-Ge were made with sandwiches of two wafers and a layer of glass frit. In most cases, the frit was deposited from a commercial tape. The tape binder was burnt out in air and the sandwich raised to the working temperature of the glass and held for approximately one hour. Bonds with satisfactory strengths were produced, but they contained numerous pores apparently resulting from entrapment of air as the glass softened and coalesced.

The next step in the bonding study was to apply a modest pressure ( $\sim 10 \mathrm{psi}$ ) to the sandwiches by dead weight loading. Enough reduction in porosity was obtained to encourage bonding of stacks of 14 elements which were subsequently sliced and bonded again with a second glass to produce 2-D assemblies. These assemblies showed considerable distortion in the form of nonuniform bond thicknesses and skewed elements and it was clear that elaborate fixturing would be required to maintain proper element orientation during pressing. It was also clear that the required control over the glass thickness could not be obtained with the tape then available. Studies on screen printing and electrophoretic deposition of glass frit were begun and the producer of the tapes, Vitta Corporation, was asked to try to make a precision tape. 
As these prototype piles were examined and attempts were made to produce electrical contacts with sputtered tungsten, a number of different types of defects were found. First, the glass was still much too porous. In addition, the bond distortion not only made photolithography difficult, but was severe enough at times to allow element-to-element contact. One of these prototype piles is shown in Fig. 6, with some details in Fig. 7 shown at higher magnification. It was also apparent that elements were being fractured during the bonding operation and were producing open circuits. The problem of fracturing of elements was relatively easily solved compared with the other problems. Many of the cracks had been introduced when the wafers were sawed from the hot-pressed slug. Visual inspection usually was sufficient to cull out defective wafers. Eddy current testing was also tried with some success. Eventually, as the sawing operation was improved and care was taken in the subsequent handling of wafers, this source of fractures virtually disappeared.

Cracks were also produced during the bonding operation. One of the major sources of difficulty was that glass extruded out of the stack and bonded the stack to the fixturing. The differential expansion between the alumina fixturing and the Si-Ge created enougin stress to cause fracture. To prevent this bonding, sheet mica was inserted at the contact points between the stack and the fixturing.

A second source of fracture in the bonding operation was bending of wafers during pressing. Part of the problem was the lack of flatness in the wafers and the ram faces contacting the wafers. Control over these parameters helped to reduce the frequency of fracture. However, most of the improvement was obtained by waiting until the stack or pile had reachea the bonding temperature and then slowly applying the pressure so that plastic 


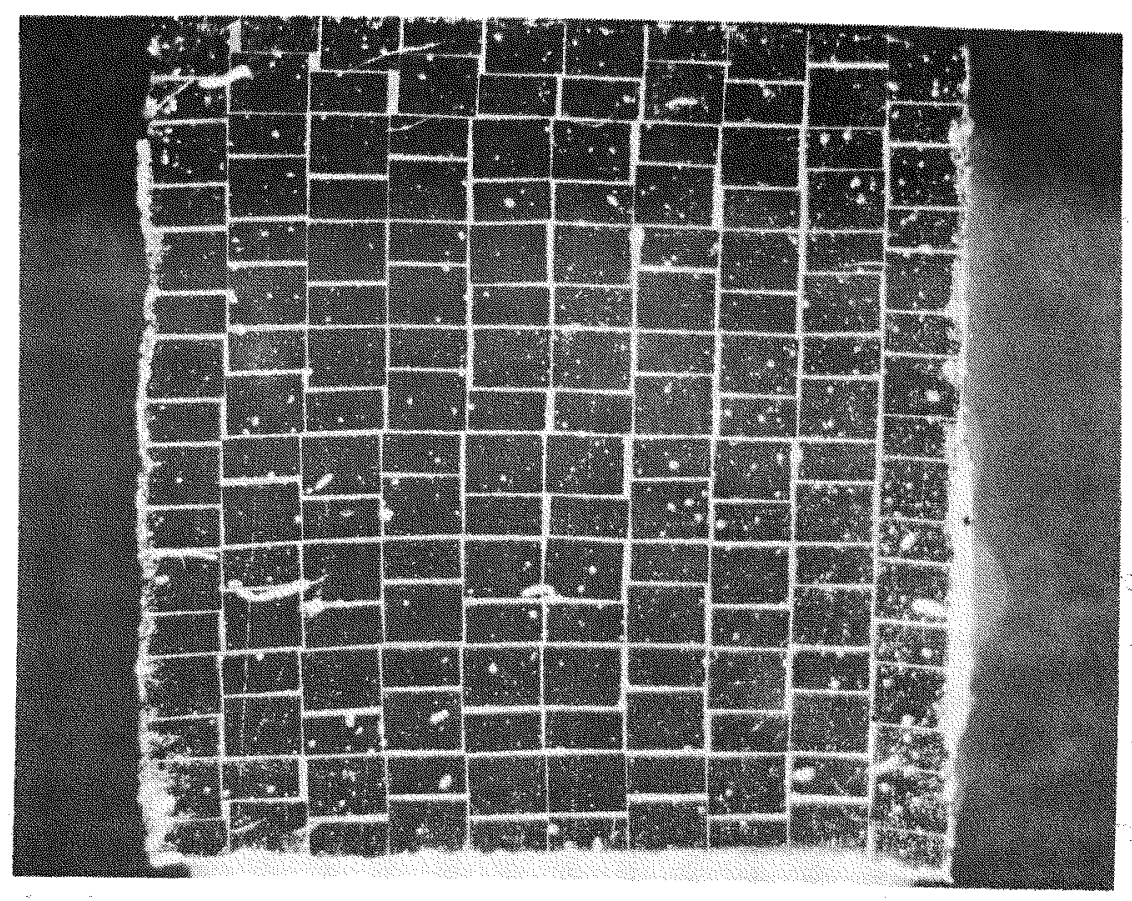

Fie. 0 Photograph of $2-D$ Thermopile

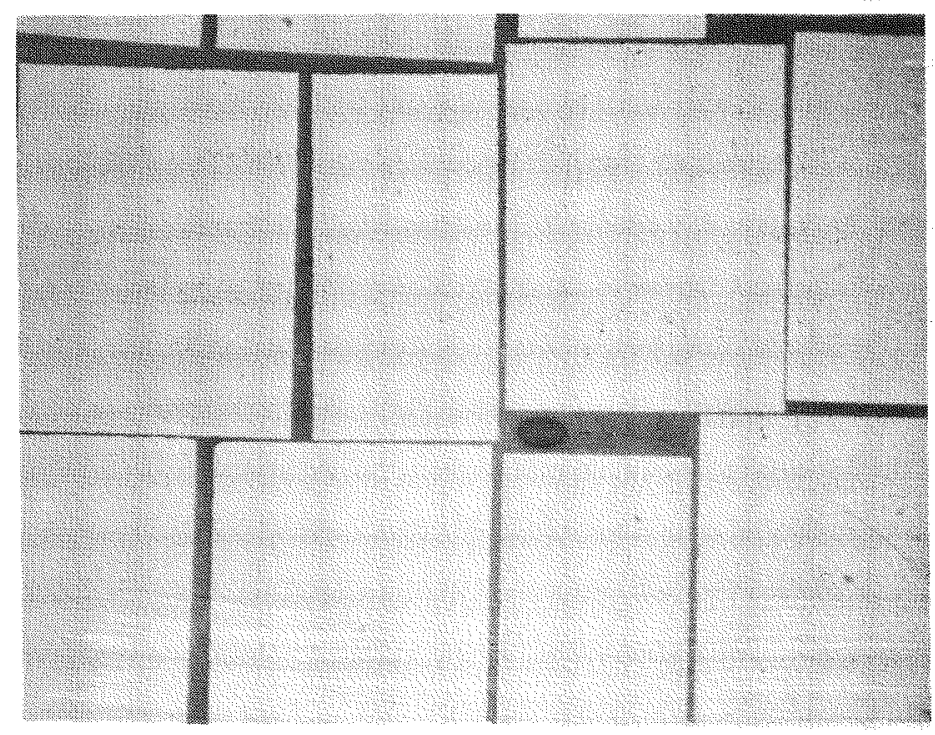

Fig. 7 Defects in 2-D Thermopile 
flow of the glass (and presumably the Si-Ge) could occur without generating large stresses. Previously, the stacks were loaded at the start of the bonding cycle.

The next efforts to reduce porosity in the bonding glass were directed at eliminating air from the glass layer before stacking the wafers. In one set of experiments, glass was put on the substrates in frit form, but prior to assembly of the wafers into a stack, the glass was melted to produce a bubble-free layer. It was found that, to prevent entrapment of air in the glass layer during this premelting, it was essential to heat the wafers in such a way that the glass nearest the wafer surface melted first. The rest of the glass was then drawn by surface tension toward the hot wafer. The altemative of melting the outer layer of glass first, produced an impermeable layer before the trapped air could escape.

In another series of experiments, the glass was introduced as a thin pore-free sheet. Conceptually, this is the simplest way to produce a bond without pores. Practically, it proved to be extremely difficult to draw the candidate glasses to less than 0.003 inch with any degree of control. Iittle success was achieved in trying to grind the glass to less than 0.004 inch. Once made, even the 0.004-inch sheets were difficult to clean and handle. Nevertheless, a number of stacks and a few piles were made with 0.004 -inch sheet glass. One of the piles is shown in Fig. 8.

Neither of these two schemes produced pore-free bonds. However, the appearance of the pores was different from those in earlier piles. Those had been numerous but relatively small. In the bonds with premelted glass and thin sheets, however, the pores were few but large. Their appearance suggested that they had been produced because of the way the glass melted during bonding. Because of the thermal gradient in the thermopile as it 


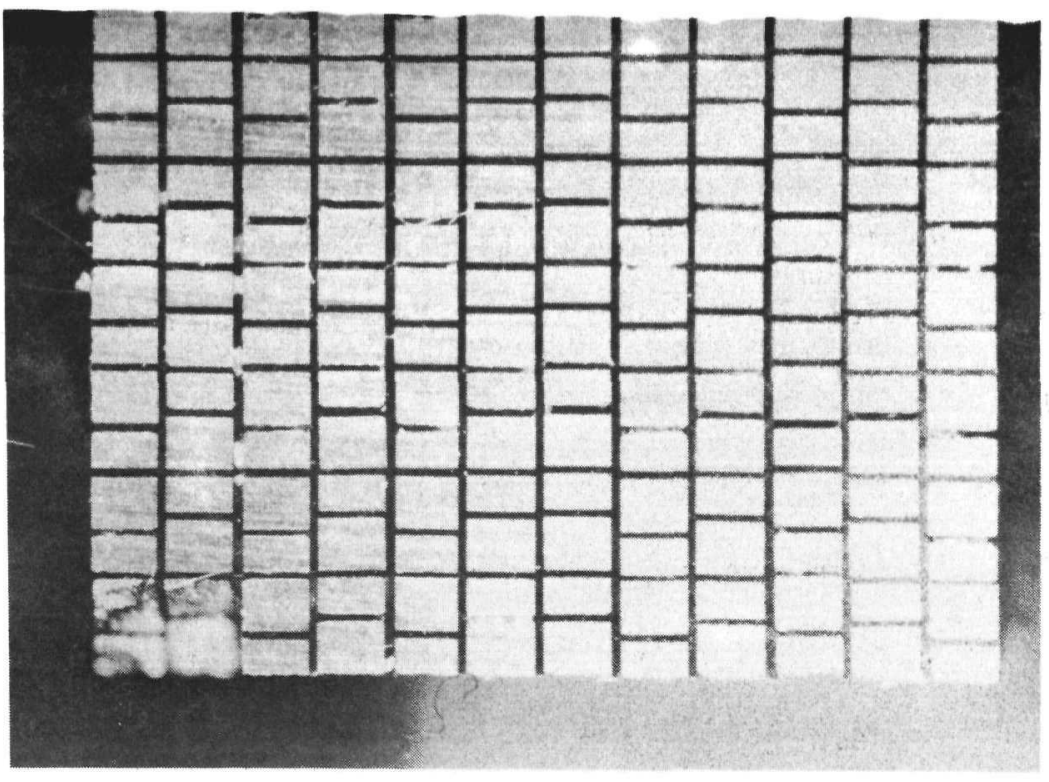

Fig. 8 Thermopile Bonded with 0.004 Inch

Thick Sheet Glass (End Face). IOX Mag.

was heated to the bonding temperature, the periphery of the bond region melted first, forming a contact area which girdled the bond region, trapping air.

To try to prevent this air entrapment, the deposition of the glass was deliberately made nonuniform by adding an extra layer of glass in selected spots. Presumably, bonding would begin at these selected spots and the bond line would then move out toward the periphery of the bond region carrying the air with it. Some improvement in porosity was obtained, but not enough to justify the loss in control over the bond thickness.

It was finally clear from these experiments that, to prevent entrapment of air in the bond layer, it would probably be necessary to evacuate the bond region before the bond was formed. It also appeared worthwhile to try higher bonding pressures. Fortunately, a vacuum hot press was available and the experiments were simple to perform. Results were very encouraging. However, bonds were still not completely pore-free. 
As the experiments in the vacuum hot press proceeded, it became clear that bubbles were produced not just by trapping air. Apparently, bubbles were being generated after the layer was completely evacuated and the bond was formed. An expeximental study (Appendix A) revealed that water and $\mathrm{CO}_{2}$, apparently dissolved in the glass when it was melted by the manufacturer, were released at temperatures above $900^{\circ} \mathrm{C}$. The release seemed to be catalyzed by contact with the Si-Ge substrate. The modifications in the process which retarded this release and resulted in almost pore-free bonds will be described in the next section.

At this point in the program it was clear that preventing distortion of the two-dimensional pile was extremely difficult. During the second bonding operation, the first bond simply was not mechanically stable. Fortunately, by this time, use of high resistivity $\mathrm{Si-Ge}$ alloys had proved feasible. With these alloys, a thernopile design employing wafers bonded in a single direction (I-D) was made possible. The development of this 1-D themopile is deseribed in the following section.

\section{BONDING PROCESS}

At the time the decision was made to build the I-D tungsten-interconnected thermopiles, the general character of the bonding process had been established. Since then, the details of various process operations have changed, with consequent improvement in the quality of thermopiles; however, the stack bonding process still consists of: (1) cleaning and oxidizing the wafers; (2) deposition of glass frit; (3) burnout of frit binders; (4) stack assembly; and (5) bonding. After slicing the stacks, a similar process (excluding oxidation) is used to bond stack slices (channels) into a thermopile. The process is shown schematically in Fig. 9. Some details of 


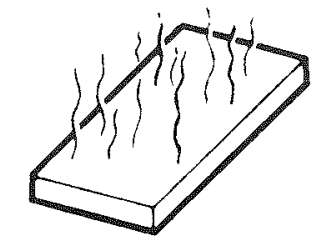

CLEAN THEN

PREFIRE $\mathbb{N ~ O}_{2}$

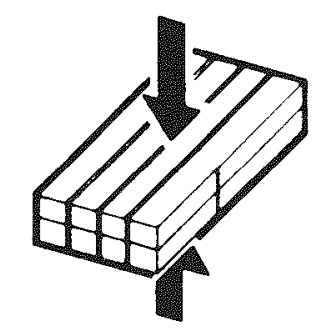

STACK AND VACUUM HOT PRESS

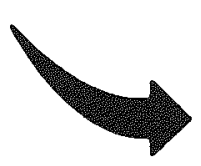

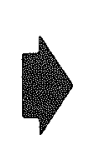

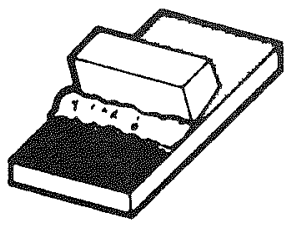
SCREEN ON 7059 GLASS

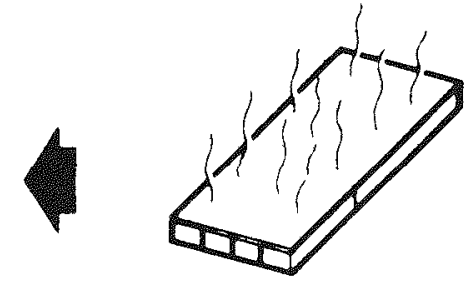

BNDER BURN OUT

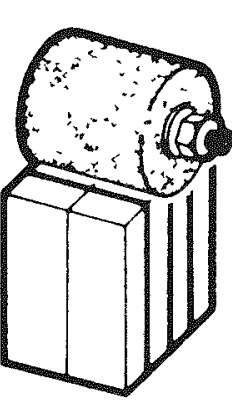

LAP SIDES

GRIND AND

POLISH ENDS

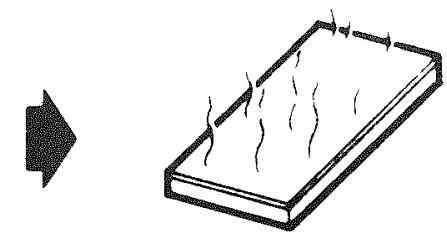

BINDER BURN OUT
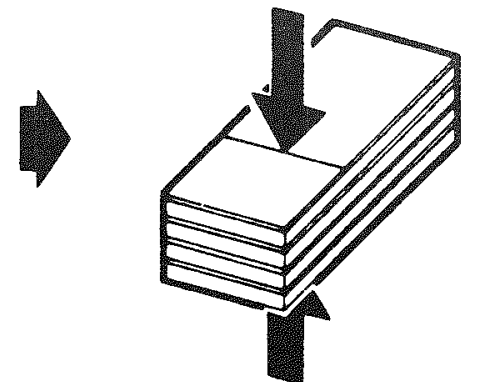

STACK AND VACUUM HOT PRESS

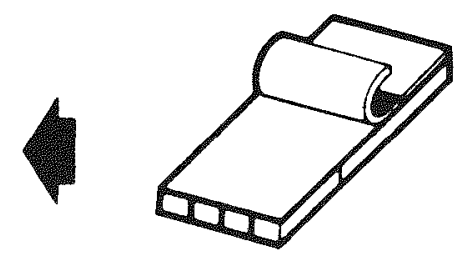

TRANSFER TAPE APPLICATION $\cdot 7052$

GLASS TAPE

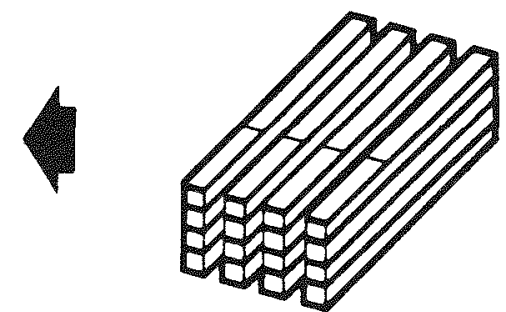

SAW

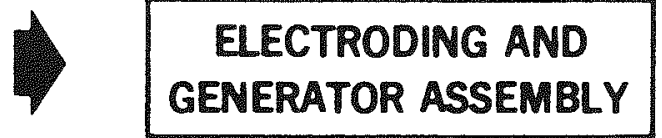

FIG. 9. FLOW DIAGRAM FOR I-D BONDING PROCESS 
the various processing steps and the important aspects of their development are described in the following section. Additional details of processes are found in Reference 4.

\section{A. Preliminary Procedures}

Cleaning Wafers--Contamination of wafer surfaces, particularly by organics, can degrade the quality of the glass bond by generating voids or by reduction of the electrical resistance. The major source for contamination is the sawing operation. An epoxy cement is used to hold the si-Ge slug in place during sawing and an organic lubricating material is used in the coolant. In addition, metal from the saw blade can be wiped onto the wafer surface.

The first step in cleaning is to prevent the lubricant from drying by immersing the mount and wafers in water immediately after sawing. If allowed to dry, the lubricant forms a very adherent residue.

Subsequently, the wafers are ultrasonically cleaned and separated from the mount. They are then placed into a Teflon holder and subjected to a sequence of cleaning steps.

Oxidation of Wafers--In one sense, oxidation of wafers is an extension of the cleaning process. Organic contaminants and residues from the chemical cleaning steps are removed from the wafer surface in this step. However, the most important function of the oxidizing process is to provide a barrier to reaction between the Si-Ge and the glass. As had been indicated in the discussion of the early development, porosity persisted in the glass bonds even after vacuum hot pressing was incorporated. The conclusion from a study, described in Appendix $A$, was that the residual porosity resulted from the release of water and $\mathrm{CO}_{2}$ from the glass. Presumably, these materials had been dissolved in the glass when it was melted in the manufacturer's 
tures where the glass frit had already softened and coalesced. As a result, the gas was unable to escape from the bond region and bubbles were formed.

It was also observed that, at the same time, a "naze" layer was form in the glass adjacent to the Si-Ge elements. Figure 10 shows this "naze" layer in $a .004$ inch sheet glass bond. The haze was attributed to attering of light from s all crystallites (possibly metallic) which had apparentIy been produced by chemzcal reduction of oxzae constituents of the glass $k$ y the Si-Ge. Although It was not lear whether the formation of the haze caused the release of the gas, It weemed evident that reaction of the glass with the Si-Ge was responsible for bouh phenomena.

Experiments using thin sheet glass showed that development of the haze layer and generation of bubbles could be delayed by introducing an oxide layer on the SiGe before applying the glass. Eventually, the $\mathrm{SiO}_{2}$ is dis-

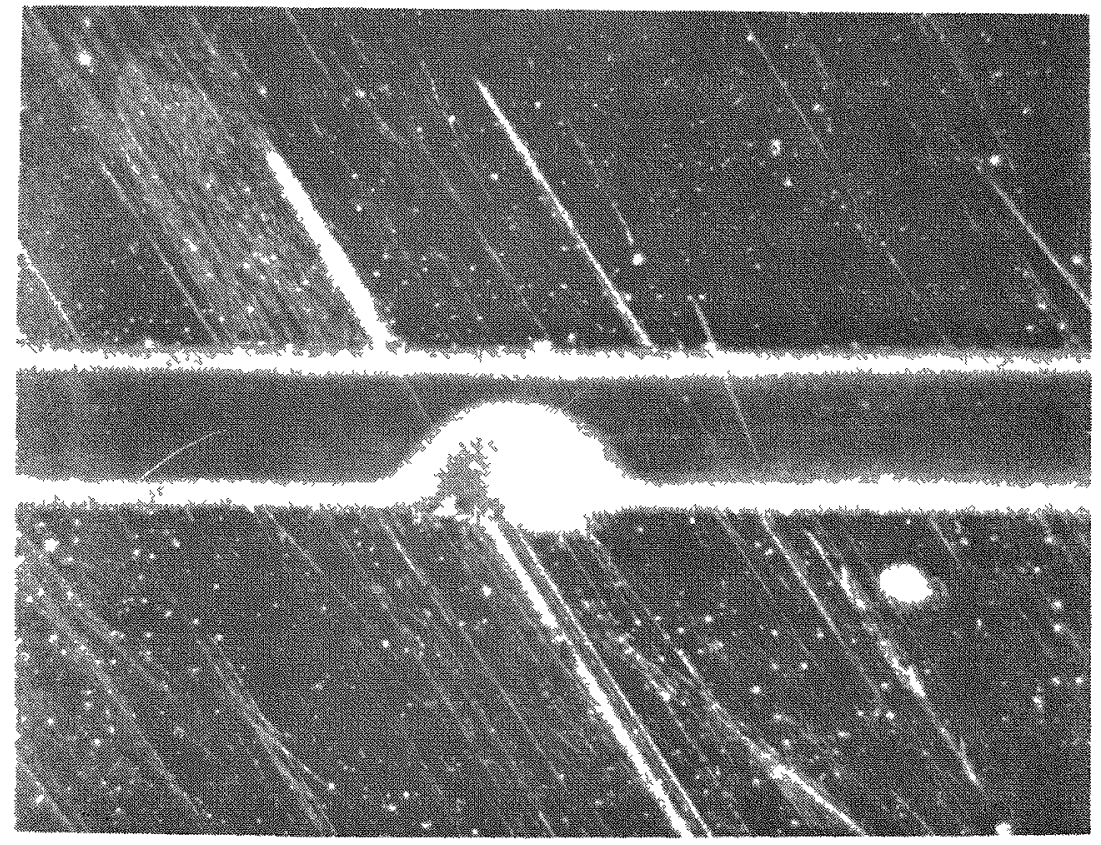

Fig. 10 "Haze" Layer in the Bond Interface. 125X Mag. 
solved by the glass and the undesirable reactions can take place. The object of the oxidation process is to provide a thick enough layer to delay the reaction long enough for the bonding cycle to be completed.

A variety of techniques for producing an oxide layer have been explored. These include thermal, plasma, and anodizing procedures in which a surface layer of the wafer was oxidized. In adition, a coating of tetraethyl oxysilane was applied to wafers and decomposed.

Thermal oxidation at $950^{\circ} \mathrm{C}$ in one atmosphere of $\mathrm{O}_{2}$ for a minimum of two hours was found to be the simplest and most effective method of producing a reaction-inhibiting coating on the wafers prior to stack bonding. Because of the lower temperature at which the second bond is made, no oxide is required for bonding the thermopile channels together.

Glass Application--As indicated earlier, the selected RTG thermopile production design required the fabrication of wafer stacks bonded together with 43 thin ( 0.001 inch) glass bonds of uniform thickness. Subsequently, two thermopile channels (adjacent slices from the same wafer stack) are bonded together with one 0.004 -inch glass bond. To provide the precision control on bond thickness required for the photolithography used in metallizing, it is essential to introduce the glass to the wafers in a uniform layer of controlled thickness.

Among the glass deposition techniques examined in this program were tape transfer, screen printing, ${ }^{5}$ electrophoretic deposition of a frit, and the use of thin glass sheets. Electrophoretic and sheet glassing were rejected because these methods would require extensive development to achieve the required precision. Although sheet glassing looked promising using 4 mil glass sheets, uniformly thick glass sheets of the required dimensions (0.001-inch thick) were difficult and expensive to produce, and, from the 
experience with .004 inch sheet, would have been extremely difficult to clean and handle. Although both screen printing and glass-tape deposition were found to have the capability for precision control and were amenable to production processes, the demonstration of precision control for tape deposition was not made until late in the program. Therefore, most of the stack bonding was performed with screen-printed glass. The primary difference between screen printing and tape deposition is that the amount of glass deposited can be varied on the production line in screen printing, whereas, in the tape process, the quantity of glass per unit area. is fixed. in producing the tape. In the development program, the flexibility of screen printing was advantageous. For production, fixing the glass quantity, so that the chance for operator error is reduced, may be worthwhile. In addition, the tape process is simpler and requires less equipment.

Early screen printing developmental studies have been described in Reference 5. Basically, the procedure consists of spreading a viscous paste of glass and binder through an opening in the screen mask onto a clean and oxidized SiGe wafer. Although commercial printing is a well-established process, the tolerance for the amount of material deposited is not normally as stringent as that imposed by the 1-D and 2-D themopile design. Consequently, the standard commercial equipment is not designed for the precision control required, and it was necessary to modify commexcially available screen printing equipment to obtain the required deposition control. The major modifications include: (1) a vacuum chuck for holding the wafer while screen printing; (2) modification of the squeegee pressure adjusting assembly for finer control; and (3) grinding of some surface areas of the printer to insure flatness and parallelism of critical components. (Fig. 11 shows the screen printer used in the development program.) 


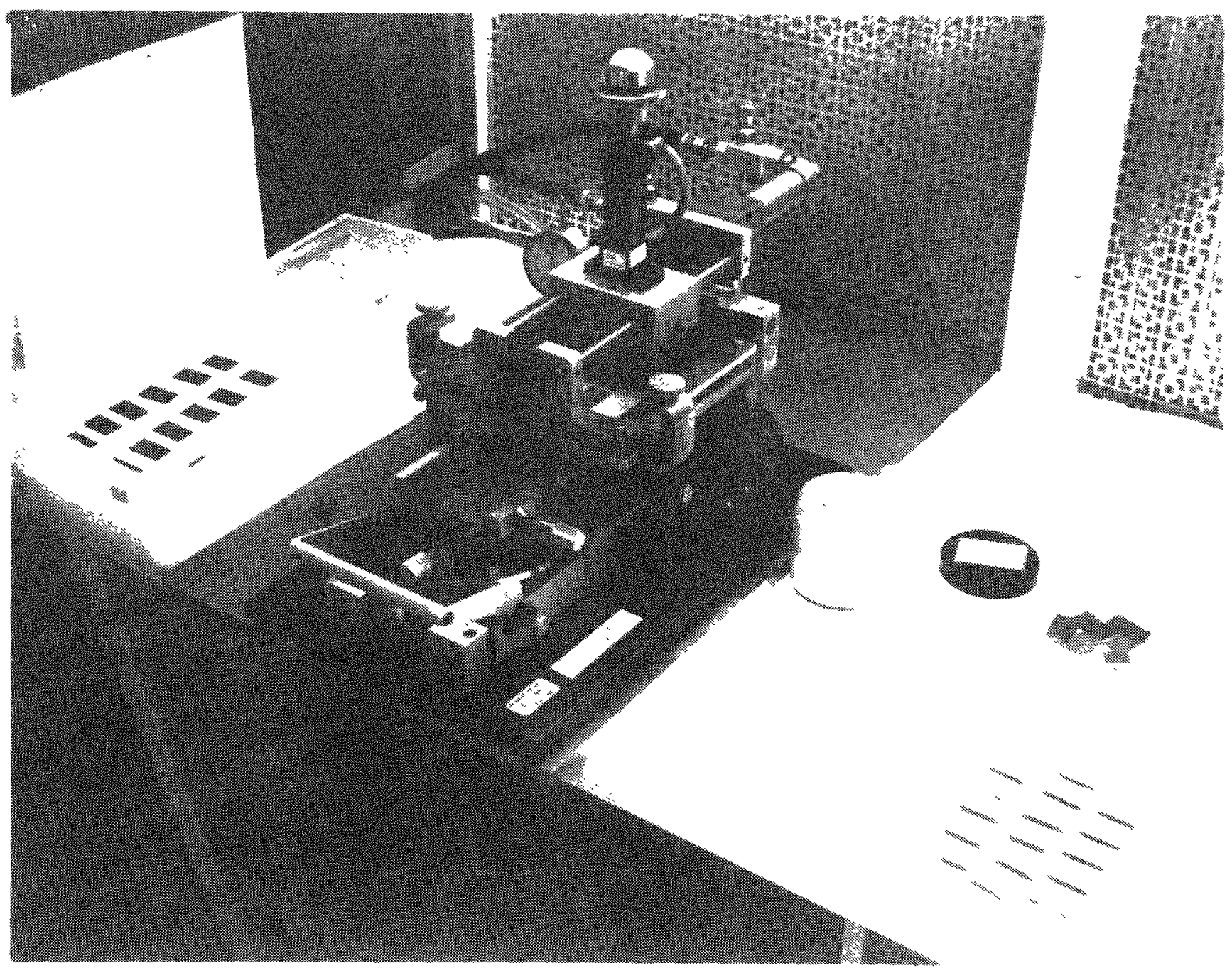

Fig. 11 Photograph of Screen Printer. 
In Reference 5, it is pointed out that the major factors determining the amount of glass deposited in screen printing are the screen mesh and wire size. Although parameters such as squeegee pressure and separation distance between the screen and the substrate influence the result enough to require control, essentially the volume of the material deposited is equal to the open volume of the screen. Thus, for a given screen size, the amount of glass deposited (in terms of weight per unit area or equivalent zero porosity thickness) is established by specifying the volume fraction of glass in the screen printing slurry.

For the development program, the pastes used for screen printing were produced by Electro-Science Laboratories, Inc. Sandia supplied them with Coming Code 7059 glass frit with an average particle size of $5 \mu$. Analysis revealed that the formulated paste consisted of about 63.8 weight percent glass frit in Texanol vehicle. The vehicle may also have contained minor quantities of other organics to give it required properties such as tackiness. The viscosity of the slurry as received was 2600 stokes at $23^{\circ} \mathrm{C}$ measured with a Brookfield Synchro-Electric Viscosimeter, Model HBT, with a SC4-14 spindle running at $10 \mathrm{rpm}$

In the present application, $44.6 \pm 1.9$ milligrams of 7059 glass frit is uniformly deposited on the 0.700 inch $\times 1.175$ inch $\times 0.007$-inch-thick wafer. This amount is about 20 percent more glass than is theoretically required to form a one-mil glass bond. The excess glass is included to compensate for extrusion of glass out of the bond region during hot pressing. Without this additional glass, voids are formed in the bonds. On the other hand, an excess of glass much beyond the 20 percent cannot be extmuded under the bonding conditions and the bond thickness will be above tolerance. 
Therefore, the giass content is controlled within \pm four percent of the specifled mount.

For deposition of the glass for the second bond, which need not be as precisely controlled as those between elements, glass transfer tape was found to be the most convenient. (Screen printing under the conditions used for the first bond would require three or four depositions to obtain the required amount of glass frit for the 0.004 -inch bond.)

The glass transfer tape is supplied by the Vitta Corporation. The glass layer contains $0.177 \pm 0.009 \mathrm{gms} / \mathrm{sq}$. in. of Corning Code 7052 glass frit. According to the manufacturer, the average particle size of the frit is below $5 \mu$. As in the case of screen printing, an excess of glass is used to allow for extrusion.

The glass bonding operations are performed under Class 10,000 clean room conditions to reduce the possibility of foreign particle contamination during glass application that could cause shorting across one-mil bonds. However, the user has no control over the manufacturing equipment, process, and environment used by the supplier in producing either the slurry or the tapes. Consequently, there is a distinct possibility of low level, difficult-to-detect, conductive particle contamination of the tape and slurry at the supplier level.

Binder Burnout--After the glass frit is deposited, the organic materials must be removed from the coatings. The presence of carbon under vacuum hot-pressing conditions could result in the formation of voids and lowresistance bonds by reaction of the carbon with glass to reduce metallic oxides and produce $\mathrm{CO}_{2}$.

To remove the organics by combustion, coated wafers are heated at $550^{\circ} \mathrm{C}$ in one atmosphere of flowing oxygen for four hours. The coated wafers are 
placed in a covered quartz boat and the oxygen is filtered to prevent particulate contamination from the furnace or the gas. At $550^{\circ} \mathrm{C}$ some sintering of the glass occurs, but not enough to cause any gross redistribution of the glass or entrapment of air. The slight sintering of the glass improves the adherence of the glass frit coating to the si-Ge.

Assembly and Fixturing--When the binder burnout procedure is completed, coated wafers or channels are assembled and enclosed in alumina fixtures in preparation for the bonding operation. Care must be exercised in handing the coated components at this stage to prevent contamination and/or damage of the coatings. During assembly, a $4 \mathrm{X}$ headoop magnifier is used to examine the frit-coated components for defects such as chips, cracks, scratches, particulate contamination, etc. All assembly operations are performed in a class 100 clean bench located in the clean room. Exploded views of wafer stack and thermopile components and fixturing are shown in Figs. 12 and 13. Processing details are presented in Ref. 4.

Early in the MC2730 RTG development program it became obvious that precision and adjustable fixturing would be required to meet thermopile dimensional and element alignment tolerance requirements. Fixture materials such as boron nitride, silicon nitride, high strength and temperature steels and alumina were tested. Alumina was selected because of its strength and inertness at operating temperatures. In addition, it is readily available and easily processed in the development shops.

The wafer stack fixture is designed to grip the assembled wafers over a small area at each corner of the stack. The remaining portion of the fixturing surrounding the assembled wafers is recessed to allow for extrusion of glass from the 43 bonds. As mentioned in section III, glass extruded from the bonds will bond the stack to the fixture. To eliminate this, mica 


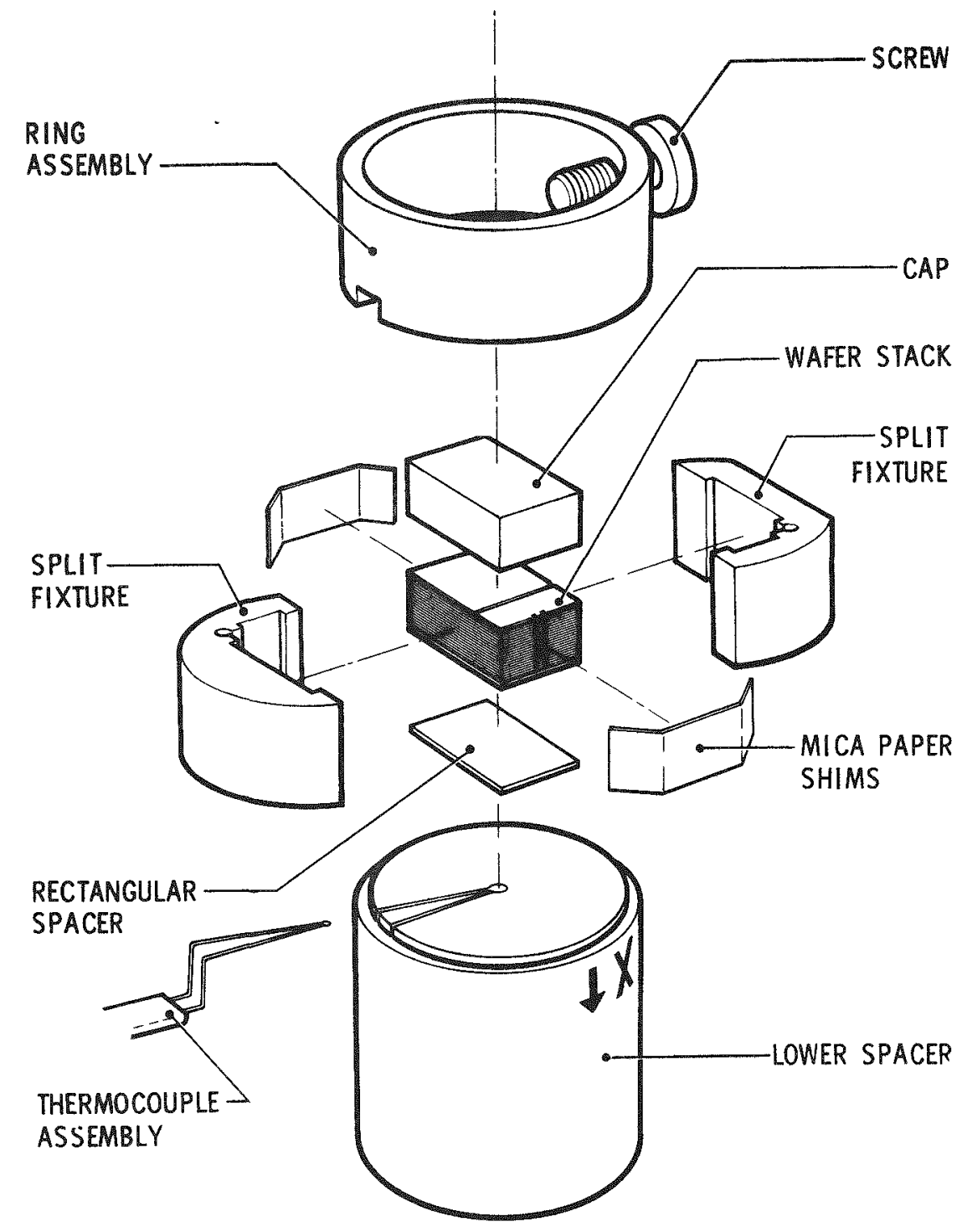

Fig. I2 Assembled Wafer Stack and Fixture.

paper shims are inserted at each end of the stack. A ceramic screw adjustable jaw was incorporated to simplify fixture loading and unloading.

\section{B. Vacuum Hot Pressing}

The reasons for employing vacuum hot pressing in the bonding process have been discussed earlier. Basically, the vacuum hot-pressing process consists of the following operations: (1) evacuating; (2) heating; and (3) pressing. However, a number of refinements have been introduced to assure the production of good quality thermopiles. The pressing cycle for 


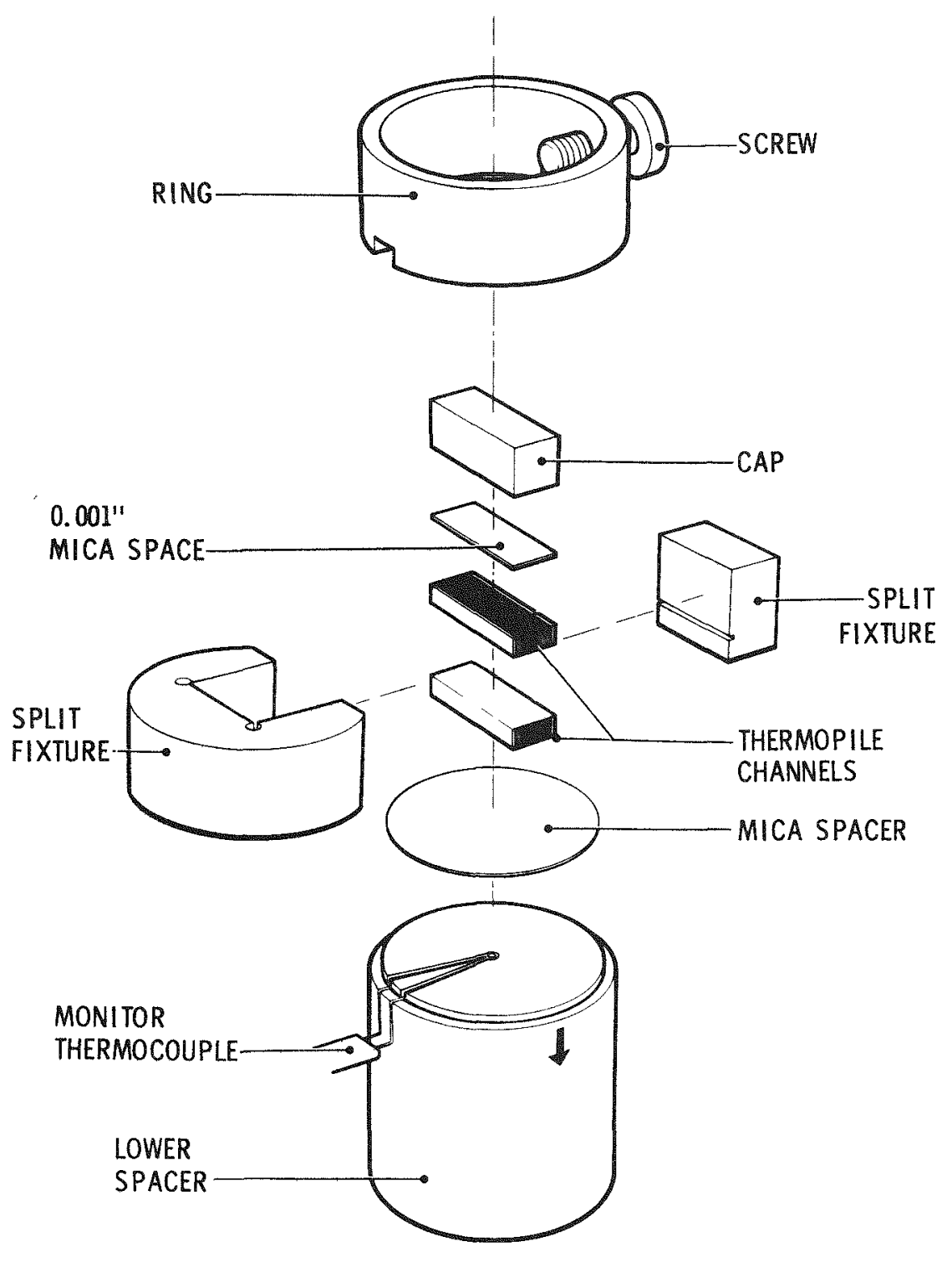

Fig. 13 Lower Spacer-Thermopile-Fixture Assembly

stack bonding is shown in Fig. 14. (The thermopile bonding cycle is shown in Fig. 15.) The distinctive features of the process are as follows:

1. Atmosphere--One-tenth of an atmosphere of oxygen is used during the initial heating stage to insure complete oxidation of organic contaminants.

2. Vacuum Hold--A vacuum hold was instituted for the desorption of gases and moisture prior to sintering. At the hold temperature $\left(600^{\circ} \mathrm{C}\right)$, the glass is rigid enough to prevent coalescence and entrapment of gases.

3. Prepressing Soak--The 10-minute prepressing soak allows the wafer stack or thermopile to approach equilibrium temperatures thus reducing the 


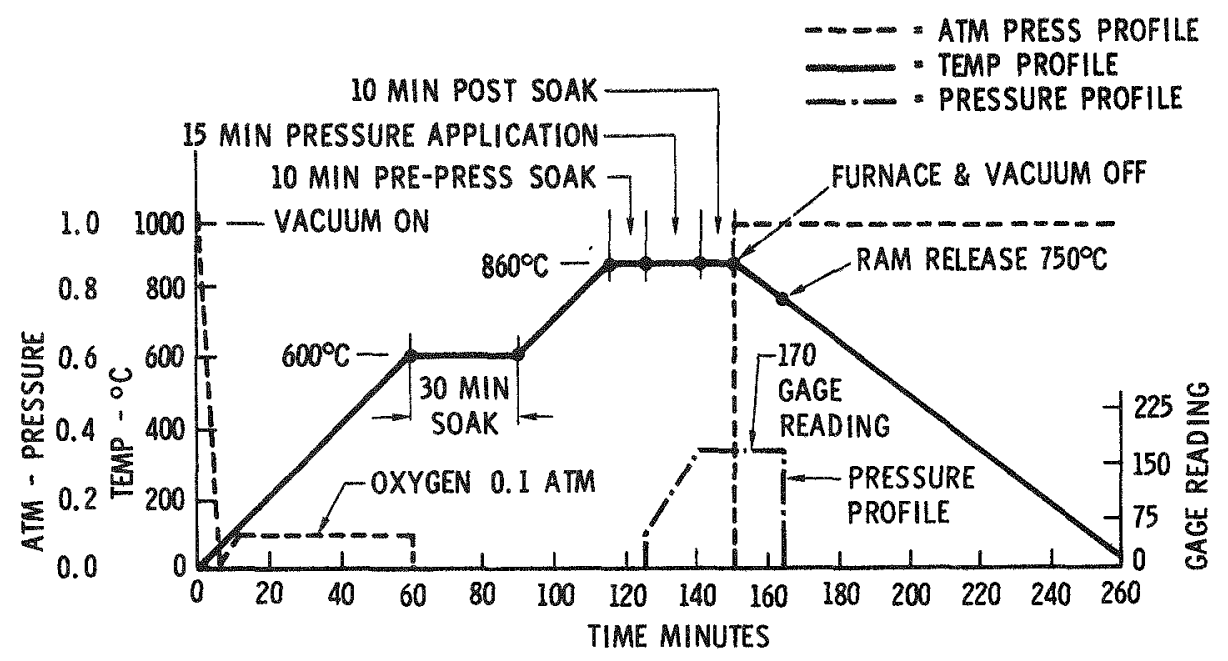

Fig. 14 Hot Pressing Cycle for Stack Bonding

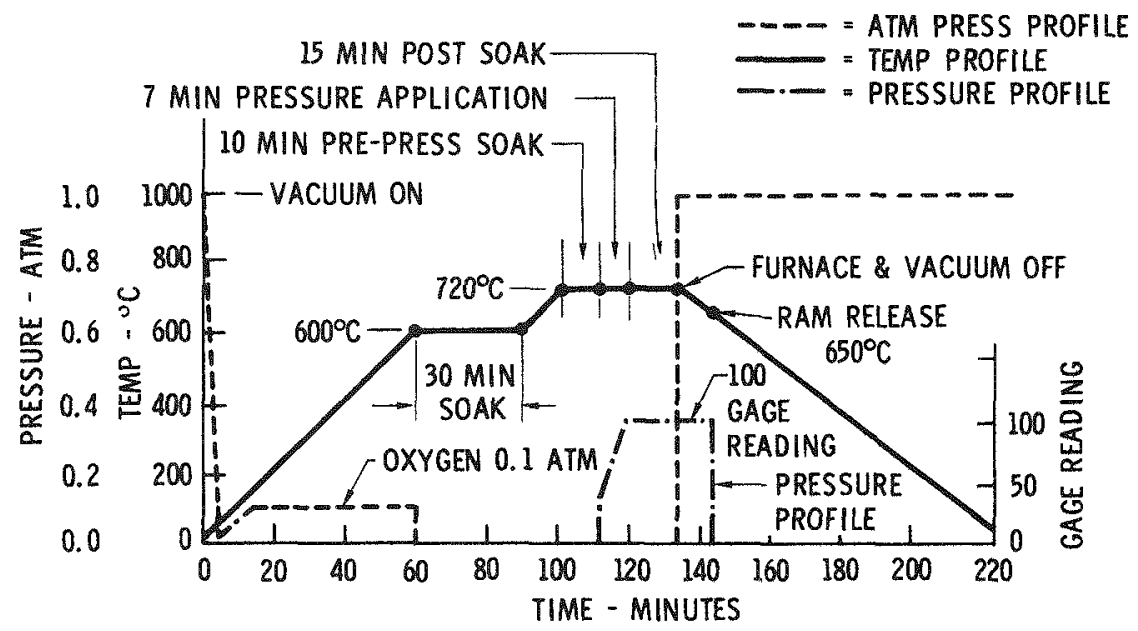

Fig. 15 Hot Pressing Cycle for Pile Bonding

possibility of element breakage and/or nonuniform glass extrusion.

4. Bonding Temperature--The first and second bonding temperatures were selected on the basis of parametric studies. In both cases, a bonding temperature of fifteen to twenty degrees above the softening point of the glasses used was found to produce the best quality bonds. In the case of the first bond, a temperature tolerance of $\pm 15^{\circ} \mathrm{C}$ was established. Below the specified range, 7059 glass is difficult to extrude and does not wet the si-Ge well enough to provide a strong mechanical bond. High temperatures result in an increased bond void content which is possibly due to reaction of the SiGe 
with the glass. Although there is no apparent undesirable reaction between 7052 glass and the substrate, the bonding temperature was minimized to prevent distortion of the first bond during the second bonding operation.

5. Bonding Pressure--The selection of bonding pressure and the manner in which pressure was applied proved to be among the most important factors in the bonding process. For production convenience, the most reasonable approach to pressure bonding flat and parallel wafer stacks and thermopiles to a nominal thickness is to press to a stop using the same pressing parameters each time. This approach was attempted at the start of the 1-D thermopile program, but it was not successful at that time. The lack of success was primarily due to variations in wafer thickness and/or the amount of frit deposited. In either case, where the cumulative thickness of the wafer stack is above nominal, additional extmusion of glass is required to press the stack to the nominal thickness. During the period when control over wafer and glass deposition thickness was marginal, wafer stacks frequently required repressing to meet dimensional specifications.

The pressing parameters having the greatest effect on glass extmion are pressure, time, and temperature. Attempts to increase extrusion by increasing the pressing temperature are limited because of the undesirable reactions between the Si-Ge and glass discussed earlier. Increasing the time at pressure could give additional extmusion, but could also promote the Si-Ge glass reactions.

Increasing pressure can also produce problems. In the early stages of pile development, fracture of wafers often occurred during pressing, with the tendency for fracture increasing with pressure. However, as the parallellism and flatness of pressing equipment improved, the strength and flatness of wafers, and the uniformity of glass deposition improved, wafers 
seldom froctured. An increase in pressure to twice the earlier values has been made possible. The pressure is brought up to the final value in 50 psi (ram pressure) increments at intervals of one minute. As a result of these modifications, ability to press to a stop was achieved.

6. Postsoak--A 15-minute soak at bonding temperature and pressure was instituted to allow additional time for glass extrusion and void closure.

7. Bonding Cycle Termination--Upon completion of the soak, furnace power is shut-off and the pressing chamber is opened to admit room atmosphere. Hydrostatic pressure is maintained on the component during the high temperature portion of the cooling cycle to reduce the possibility of void formation and growth. Pressure is released before the strain point temperature is reached to prevent fracturing of the glass bonds. Fixtures and bonded components are removed from the hot press at temperatures below $200^{\circ} \mathrm{C}$.

\section{WAFER STACK AND THERMOPIIE DEFECTS}

Thermopile and element misalignment, first- and second-glass insulating bond end face voids, and interelement shorts were the three major types of defects encountered in the fabrication of one-dimensional MC2730 RTG thermopiles. To date, defects have not been eliminated, but they have been diminished to an acceptable level. Many of the causes and corrective measures have been discussed earlier in this report. The purpose of this section is: (I) to expand on and clarify information presented in preceding sections, and (2) to present information not covered earlier, with the objective, in both cases, of supplying analytical information useful for technology transfer. 
A. Thermopile Element Misalignment

Alignment of one-dimensional thermopile elements is less critical than the alignment of two-dimensional elements because of element size, difference in the number of bonds, and the size and patterm of the tungsten electrodes. Nevertheless, significant element alignment problems and other bond defects were encountered in the fabrication of 1-D thermopiles. Figure 16 shows the major types of transchannel element alignment problems that were encountered in the fabrication of 1-D thermopiles. Each sketch in Fig. 16 represents one type of alignment problem. Often, in practice, a combination of two or more alignment defects were detected in the same thermopile. Nearly all of the alignment problems could be attributed to inadequate pressing fixtures and/or dimensional mismatching of thermopile channel materials. Dimensional Mismatch--The use of channels sliced from different stacks can result in the type of misalignment shown in sketches $A$ and $B$ of Fig. 16. Within-tolerance variation in stack height due to variation in wafer and bond thickness is the cause of this type of misalignment. Correction of this problem was accomplished by using adjacent channel slices for the fabrication of thermopiles.

Recently, with the attainment of the ability to press to a stop, as discussed in the preceding section, stack height differences have been minimized. As a result, the need for using adjacent channels will not be as critical in the future. In addition, the use of 0.014 -inch-thick top and bottom stack wafers, to provide excess material for machining, may be eliminated.

Thermopile Fixtures-- The primary cause of thermopile channel swiveling and chevroning (Fig. $16 \mathrm{c}$ and d) during the bonding operation, was determined to be loose fixturing. At the start of the 1-D thermopile program, a 


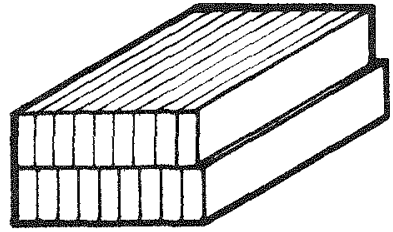

(A)

DIMENSIONAL

MISMATCH

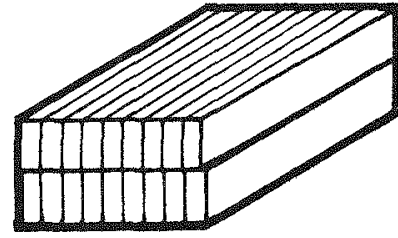

(B)

DIMENSIONAL MISMATCH

(TAPERS)

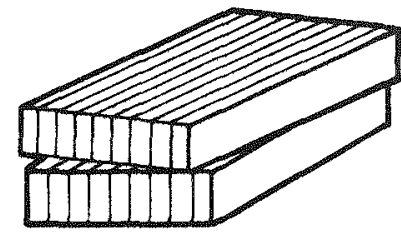

(C)

SWIVELING (LOOSE FIXTURES)

(D) CHEVRONING

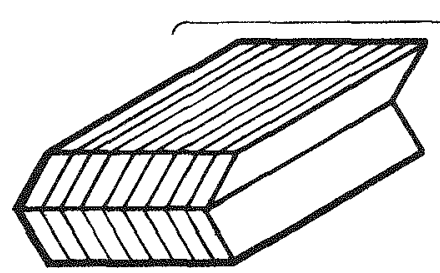

(a)

(LOOSE FIXTURES)

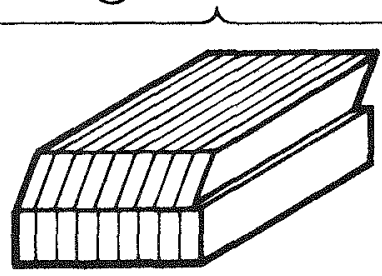

(b)

(DIMENSIONAL MISMATCH)

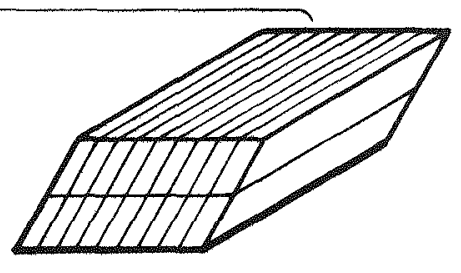

(c)

(STACK SLICING)

Fig. 16 Interelement Alignment Defects

fixed width fixture was used to press all piles. Because of the range in stack height permissible under the specifications, the separation between the stack slices and the fixturing could be as much as 0.008 inch. Attempts to correct the problem by using additional mica paper shims were abandoned because of the difficulty of loading the fixture with as many as three shims at each comer of the fixture. As an alternative, a new fixture with a ceramic screw adjustable jaw was fabricated. The fixture was also modified in respect to gripping area and glass extmusion clearance. The jaws 
now tighten down on the entire surface of the top and bottom channel elements. A 0.050-inch width and depth groove surrounds the second bond area to permit clearance for glass extrusion. The use of this fixture has eliminated all major alignment problems. Minor alignment problems were minimized by allowing enough clearance around the adjustable jaw to compensate for slight tapers in channel dimensions and by eliminating the use of mica shims.

B. Voids

Voids have been a problem from the early stages of the RTG thermopile development program. The sources that have been identified are listed below:

1. Gases and moisture physically adsorbed on glass frit.

2. Insufficient amounts of glass to permit full coverage of the wafer.

3. Incomplete binder burnout.

4. Too low a bonding temperature to permit good glass flow and wetting of the wafer.

5. Gases and moisture dissolved in the glass frit. (Appendix A)

First Bond Voids--The first 20 one-dimensional wafer stacks fabricated in this program varied in void content from fair to poor on an arbitrary scale. The best stack had a few randomly located spherical voids. The poorest stacks had a large number of voids. Most were located at the center of the stack. In addition to spherical and elongated bubble voids, (Figure 17), irregular voids, caused by the breakout of glass and si-Ge at their interface (Figure 18) were detected. Interface defects and the locam tion of the voids in the stack suggested that the stack was not attaining a uniform and high enough temperature to allow good wetting of the siGe and void migration. Subsequently, the pressing temperature was increased and 


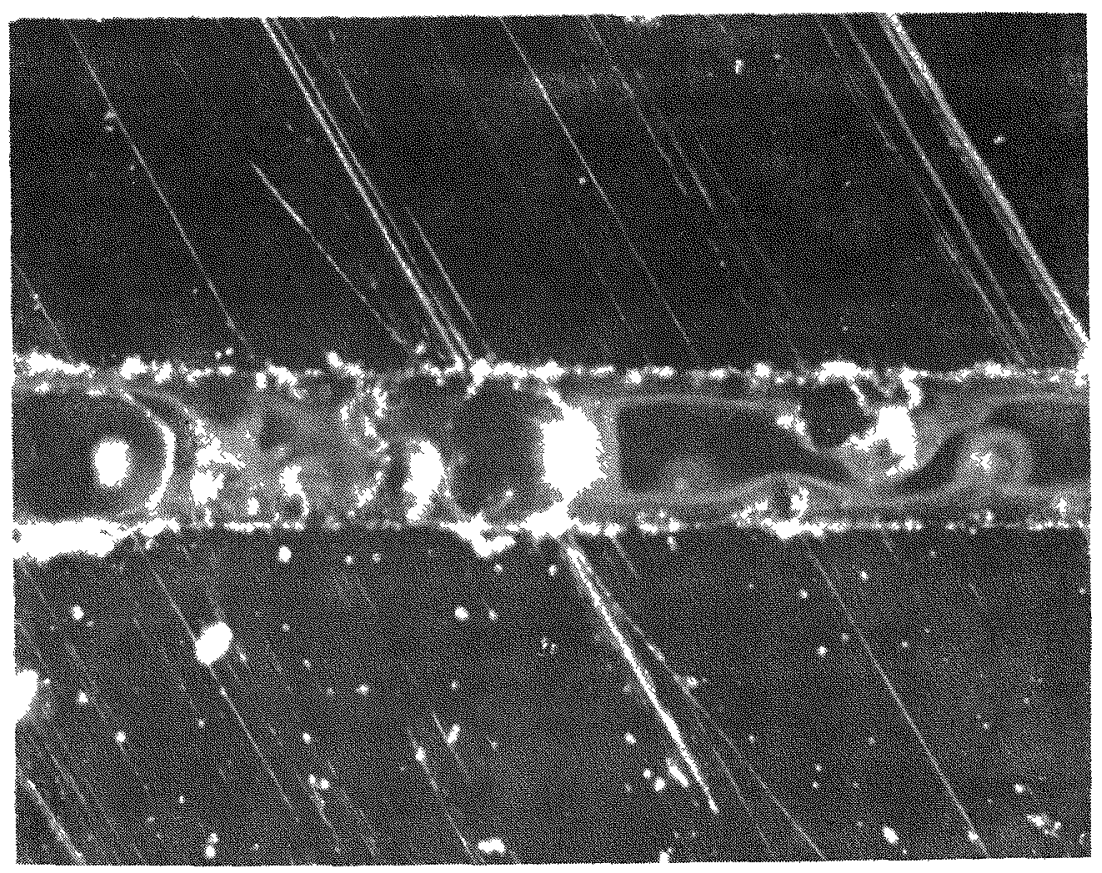

Fig. I7 Voids in the Glass Bond.

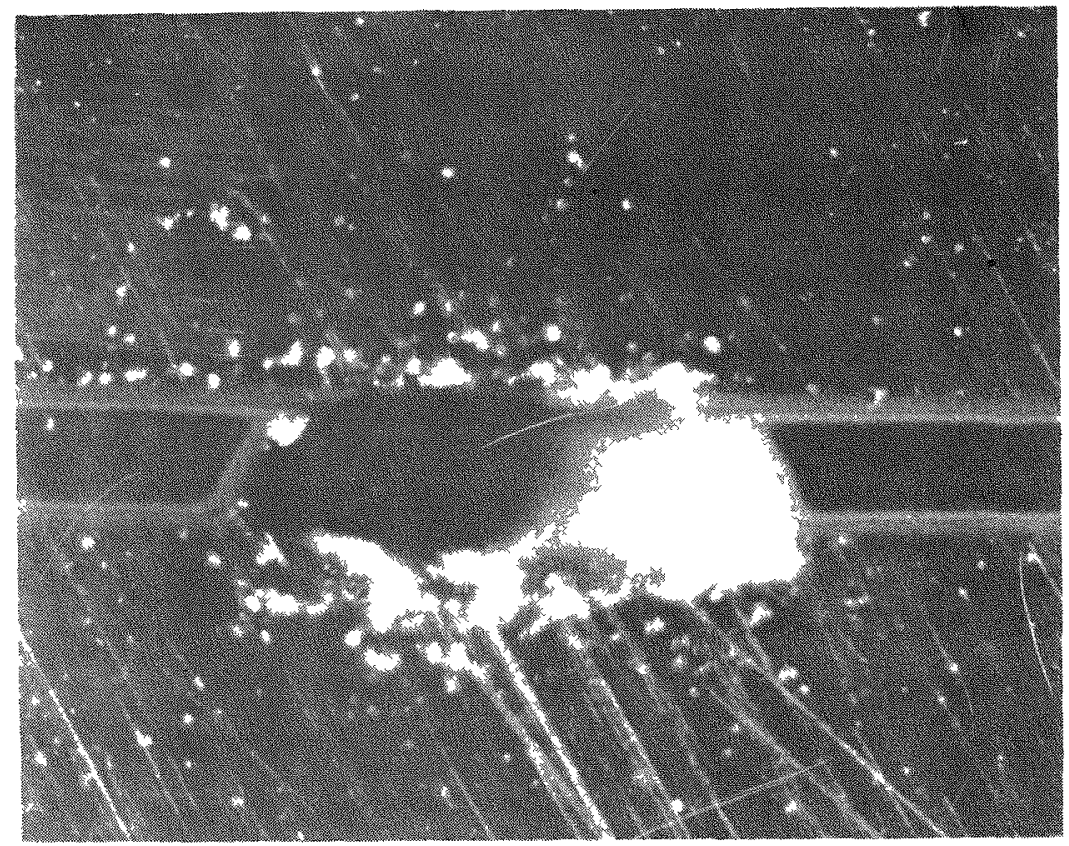

Fis. 18 "Breakout" at the Bond Interface. 
the prepress soak was initiated. These process modifications resulted in the elimination of breakout and a very substantial reduction in all other types of voids. The few remaining voids appeared to be due to gases trapped in the initial stages of bonding rather than evolved during the final stages. The inclusion of a low temperature vacuum hold and extension of the postpress soak, which are discussed in the preceding section, produced the desired additional reduction in first bond void content.

Second Bond Voids--In early piles, voids in the second bond were found to be due primarily to a deficiency in glass content as evidenced by a lack of glass extrusion. Glass tape with an increased glass content per unit area was substituted. This change, combined with the addition of a low temperature vacuum hold, pre- and postpress soak, and an increase in pressing temperature, has resulted in the production of void-free second glassing $0.004-i n c h$ bonds.

\section{Shorts}

Interelement shorts (low electrical resistance) measuring greater than $100 \mathrm{ohms}$ were considered to be acceptable for early one-dimensional thermopile prototype assemblies. The shorting problem has been significantly reduced but not eliminated. Two modes of shorting--surface and intemal--have been detected.

Surface Shorts--During the initial production period, optical and SEM examination of sawed thermopile channel surfaces revealed that, in some cases, a conductive material bridged the 0.001 -inch glass insulating bonds. The majority of the surface shorts were associated with "metal" markings introduced during the sawing operation (Fig. 19). A microprobe analysis detected $\mathrm{Si}$, Ge, Fe, $\mathrm{Cr}$ and possibly $\mathrm{Ni}$ in the marked area of an "as sawed" 


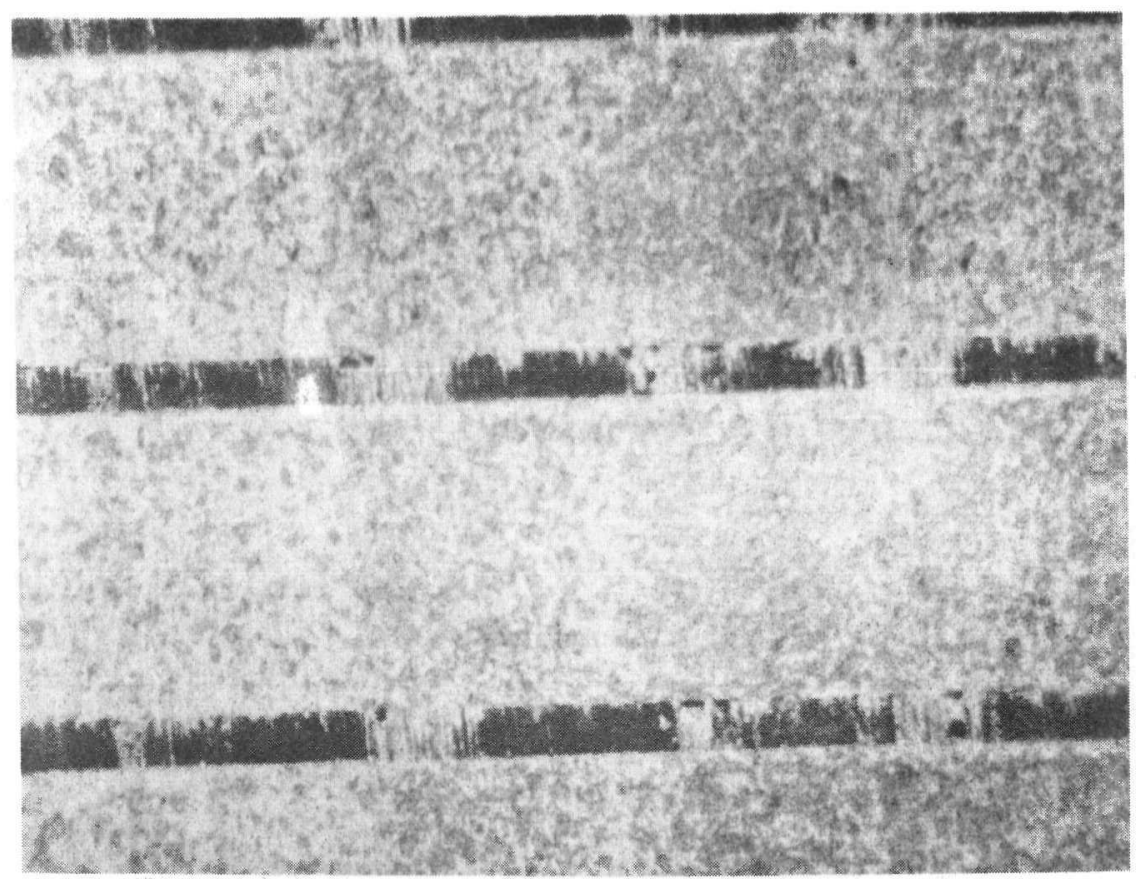

Fig. 19 Conductive "Metal" Marking Produced in Sawing. 200X Mag.

sample. The source of the $\mathrm{Fe}, \mathrm{Cr}$, and $\mathrm{Ni}$ was apparent. $\mathrm{Y}$ the sta.inless steel sa.w blade.

At the time the metal-marking was detected, a cleaning procedure was being used which removed the $\mathrm{Fe}, \mathrm{Cr}$ and $\mathrm{Ni}$. To remove the $\mathrm{Si}$ and Ge, a lapping procedure was initially employed in the processing. Subsequently, a dilute $\mathrm{HF}^{-\mathrm{HNO}_{3}}$ etch replaced the lapping procedure.

Following the introduction of the lapping procedure, the number of shorts dropped from an average of 3.6 per channel for 72 channels to an average of 0.8 per channel for the next 124 channels. After etching was begun the average dropped to 0.5 per channel for the next 164 channels. Not all of this reduction should be attributed to elimination of metal marking. The short test does not discriminate between intemal shorts and surface shorts and a number of process changes were introduced during this period which should have reduced the number of internal shorts. 
Internal Shorts--Internal shorts are still being studied. No interchannel ( 3 to $5 \mathrm{mil}$ bond) shorts have been detected to date. It appears probable that internal shorts are due to conductive particles about the size of the first bond thickness. The most likely sources for conductive particulate contaminants are:

1. The screen printing operation,

2. Wafer handing (tweezers) operations,

3. The screening paste or glass tape, and

4. Atmospheric and/or equipment contamination. Contamination due to screen printing and glass frit sources has been discussed earlier in this report. Tweezer handling of screened parts can cause small particles to chip from wafer edges due to localized high pressure. Atmospheric contamination can occur during binder burnout and wafer stack assembly operations. One possible nonparticulate source of shorts may be bridges formed by reduction of metallic oxide components of the glass.

On the assumption that shorts are produced by conductive particles introduced during processing, a number of process and equipment modifications were recently added to those already in effect. The use of gray room and clean bench facilities during frit deposition, binder burnout, and stack and pile assembly procedures was introduced during the two-dimensional thermopile development program. Mechanical inspection of cleaned wafers is now performed on a clean bench in the gray room. Tweezers have been modified to broaden their contact area, thus reducing high pressure points on wafer edges. A vacuum pickup wand is used where possible. As indicated earlier, filters have been added to the gas lines that supply oxygen for the oxidation of wafers and binder burnout and large fused silica containers are used to protect wafers from furnace-produced contaminants. When analysis revealed the 
presence of carbon after the binder bumout procedure, the binder burnout time and temperature were increased.

An electrical bumout procedure was devised as a temporary measure to remove existing shorts ( $<10,000 \mathrm{ohm}$ bond resistance) prior to the second glass bonding operation. Short removal was accomplished by applying a dc voltage between shorted elements. Initially, it was found that most low resistance bonds required less than 10 volts and a few hundred milliamps for less than one second to obtain high resistance ( $>100,000$ ohms) bonds. Approximately 85 percent of the shorts subjected to this treatment were removed prior to the bonding of thermopile channels. Thermopile tests showed that about 50 percent of the treated shorts returned after the second bonding operation. Moreover, new shorts in previously open bonds occasionally appear. Better results have been obtained with a 20-volt pulse treatment for 211 low resistance bonds. Less than 20 percent of the shorts returned after the second bonding operation.

One of the problems with the electrical bumout of shorts is that the heat pulse generated in the vicinity of the short can produce mechanical damage in the glass and the adjacent elements. Therefore, since the rate of short occurrence has also decreased and there was little correlation between channel and pile shorts, the treatment has been discontinued.

Infrared microscopy, liquid crystals, and Tempilac (a heat sensitive coating) have been used to locate heat producing shorts. These techniques and materials have been used to determine the general location of shorts that do not burn out during the 20-volt de pulse treatment. The infrared microscopic technique is the most sensitive but also the most complex. It would require the development of an automatic scanning and probing mechanism to be useful. The liquid crystal and Tempilac approaches are preferred 
because of their simplicity. Encapsulated liquid crystal, in sheet form, is presently being used to locate shorts.

Three thermopile channels were lapped and polished to expose the shorted bond glass. To date, optical microscopic examination and microprobe analysis have failed to establish the cause of the shorts. Although the shorts location procedure is relatively rapid and simple, the grinding, lapping and polishing to expose the shorted bond without damaging the shorted area of the bond is a delicate and time-consuming operation. Even if the operation is successfully accomplished, there is some question as to whether a statistically significant number of specimens can be analyzed to identify the primary cause(s) for internal shorting of channels and thermopiles.

Summary of Short Data--One hundred fifty-four 1-D thermopiles have been tested since the one-dimensional thermopile program began. Most of the equipment and process modifications for reducing and treating shorts were initiated after the first 30 piles were fabricated. The pertinent bond resistance data for the first 30 piles are compared with the last 124 thermopiles in Table II.

The data show a marked reduction in low resistance bonds for the last 124 thermopiles. The fraction of short-free piles was increased by about a factor of four and the fraction of piles containing bonds with a resistance $<100 \Omega$ has decreased by about 58 percent. It appears doubtful that the yield of totally short-free piles can be significantly increased until the shorting mechanism is identified and, if possible, the cause eliminated. 


\section{TABLE II}

FIRST BOND RESISTANYE DATA

Piles with

All Bonds $>10 \mathrm{k} \Omega$

(Short Free)

Bonds $<10 \mathrm{k} \Omega$

(Shorted)

Bonds $<100 \Omega$

(Unacceptable)

Bonds With

Resistance $>10 \mathrm{k}$

(Short Free)

Resistance $<10 \mathrm{k} \Omega$

(Shorted)

Resistance $<100 \Omega$

(Unacceptable)

$\frac{\text { First } 30^{*}}{\text { Number }}$ Percentage

9.1

90.9

50.

$14 / 28$

$26 / 122$

21.3

Last $124^{* *}$

42.6

$70 / 122$

57.4

$52 / 122$

Number Percentage

98.9

$1805 / 1892$

95.4

$10,381 / 10,492$

$110 / 10,492$

1.0

$87 / 1892$

4.6

1.1

$32 / 10,492$

0.3

$26 / 2408$

$32 / 10,492$

\section{3}


1. W. R. Abel, et a1., 1334, "MC2730 Interim Development Report," Sandia Laboratories Report SC-DR-72-0863, February 1973.

2. RTG Advisory Committee, "RTG Project Quarterly Progress Report, October December 31, 1971," Sandia Laboratories Report SC-PR-72-0073, February 1972.

3. J. V. Dalton and J. Drobek, "Structure and Sodium Migration in Silicon Nitride Films," J. Electrochem. Soc. 115, 865 (1968).

4. J. Matsko, F. Philgreen, R. Snidow and C. Tuthill, "RTG Thermopile Glass Bonding Process Description (ID-W)," Sandia Laboratories Report SIA-730613, August 1973.

5. C.W. Jennings, "Screen Printing of 1720 and 7059 GIass Insulating Bonds for the Radioisotopic Thermoelectric Generator," Sandia Laboratories Report SLA-73-0080,

6. Robert G. Dosch, 5521, "Electrophoretic Deposition of 7059 Glass on SiGe," Sandia Laboratories Report SC-TM-72-0341, May 1972. 


\section{APPENDIX A}

\section{A.1. VODD RRODUCTION THRU RELEASE OF DISSOLVED GASES FROM GLASS}

Although the introduction of the vacuum hot-pressing procedure substantially reduced the porosity of the glass bonds in the RTG thermopiles, some porosity remained. Even when thin sheet glass was substituted for the frit, many bubbles were still formed at the glass-Si-Ge interface. Apparently the air trapped in the glass frit was not the only source of porosity.

An alternative source of the gas which produced the porosity was the glass itself. It was recognized that substantial amounts of certain gases are dissolved in most commercial glasses. (Ordinarily these dissolved gases are so benign that their presence is ignored.) Raw materials for the glass batch are often carbonates or hydrated materials (and occasionally sulfates)。 Some of the $\mathrm{CO}_{2}$ and water is usually retained when the batch constituents are melted to form the glass. The melting process itself can also introduce $\mathrm{CO}_{2}$ and water since most glasses are melted in gas-fired furnaces where the combustion products pass over the melt surface.

The questions in connection with void production were: Where was the gas coming from? Why was it being released? What could be done to prevent the release? In an attempt to answer those questions, R. J. Eagan ${ }^{\dagger}$ initiated experiments using a hot-stage microscope. In most of these expeximents small fragments ( $2 \mathrm{~mm}$ diameter) of sheet glass were placed on Si-Ge (and other substrates) which were then heated in various atmospheres while being observed through the microscope.

In the initial experiments it was observed that when 7059 glass was melted on either $\mathrm{P}$ - or $\mathrm{N}$-type Si-Ge wafers in air or argon, bubble formation occurred between $950^{\circ} \mathrm{C}$ and $1000^{\circ} \mathrm{C}$. In a pure oxygen atmosphere, bubble FMemorandum of Record to Distribution from R. J. Eagan, G. J. Jones, and G. C. NeIson on "Status of Studies of Gas Evolution at Glass-SiGe Interface, "January 3, 1972. 
formation was retarded but not eliminated. With 7059 on a Pt substrate, no bubbles were generated under the conditions above. On an alumina substrate only a few small bubbles appeared.

These observations suggested that the gas was evolved as a result of reaction of the glass with the Si-Ge. To determine if the reaction was caused by impurities on the Si-Ge, samples were given various surface treatments, including diamond grinding, etching in hydrofluoric acid, and oxidizing for 1 hour at $900^{\circ} \mathrm{C}$. In addition, chill cast Si-Ge and pure silicon single crystal samples were used as substrates. In each case, when 7059 glass was subsequently melted on the substrate, gas bubbles were formed. (Some reduction of gas evolution was observed for the oxidized sample.) Apparently the Si (and perhaps the Ge) were reacting with the glass.

To determine the nature of the gas evolved in bubble formation, the next series of experiments was performed in a vacuum chamber with a residual gas analyzer (RGA) to monitor the mass spectrum. G. J. Jones (2334) and G. C. Nelson (5825) performed the experiments.* Visual observations of bubble bursts were correlated with rapid, large increases in intensities of mass peaks. Bubbles were first seen to break the surface of the glass at approximately $925^{\circ} \mathrm{C}$. In all experiments the major outgassing products were at mass $44\left(\mathrm{CO}_{2}\right), 28(\mathrm{CO}), 18\left(\mathrm{H}_{2} \mathrm{O}\right), 17(\mathrm{OH}), 16\left(\mathrm{CH}_{4}\right)$, and $12(\mathrm{C})$. (While these mass numbers are not unique to the molecules in parentheses, the relative intensities of associated peaks are consistent with the identification shown.) Gas content varied from bubble to bubble, with some releasing primarily $17(\mathrm{OH})$ and $18\left(\mathrm{H}_{2} \mathrm{O}\right)$, while others released principally $44\left(\mathrm{CO}_{2}\right), 28(\mathrm{CO}), 16\left(\mathrm{CH}_{4}\right)$, and $12(\mathrm{C})$.

SignificantIy, when Pt or alumina substrates were used in these vacuum melting experiments, bubbles were also produced in the glass, even though Ibid., page 45 . 
they had not been produced with an overpressure of one atmosphere. The only difference between using these substrates and using si-Ge in vacuum melting was the development of a gray haze in the glass contacting Si-Ge while the glass remained clear on the other substrates.

At this point in the study, it appeared worthwhile to determine if the glass could be completely degassed by vacuum melting so that subsequent melting on Si-Ge would produce no bubbles. The results were encouraging. After vacuum melting for $2 \frac{1}{2}$ hours at $1200^{\circ} \mathrm{C}$, no bubbles were observed when the glass was remelted on Si-Ge in air. Very few bubbles appeared when the glass was remelted in vacuum on either Pt or Si-Ge. Chemical analysis of the glass before and after vacuum melting showed essentially no change in the major constituents. $\left(\mathrm{H}_{2} \mathrm{O}\right.$ and $\mathrm{CO}_{2}$ were not measured.)

While it would have been relatively simple to vacuum pre-melt all the glass to be used in thermopile bonding, there was no assurance that the glass could be kept gas-free until the bonding operation. In particular, it was recognized that comminution of the vacuum melted glass to the frit form required for the bond would be very difficult to accomplish without readsorbing water and, perhaps, $\mathrm{CO}_{2}$. To determine, qualitatively, the result of regrinding, some of the vacuum melted 7059 glass was ground in a boron carbide mortar. When the resultant powder was remelted on siGe in the hot stage microscope, bubbles appeared, the number and size increasing as the frit particle size decreased. When the frit was heated in the RGA, water was released initially (before the glass melted) and finally, above $900^{\circ} \mathrm{C}$ (after melting the glass), the mass $28(\mathrm{CO})$ and $44\left(\mathrm{CO}_{2}\right)$ peaks increased in a manner associated with bursting of small bubbles.

A possible alternative to vacuum melting the glass to eliminate voids in bonding was to modify the glass so that the reaction with the siGe that 
resulted in gas release could not take place. A clue to the nature of the responsible reaction was the generation of a "haze" layer in the glass near the SiGe interface concurrent with bubble formation. The haze layer seemed to be produced by light scattering from crystalline inclusions (perhaps metallic) in the glass. Apparently these small crystallites were generated by chemical reduction of low-energy oxides in the glass. The Si, and, perhaps the Ge, in the Si-Ge provided the electrons. The possibility that diffusion of some constituent of the Si-Ge or of the glass might be diffusing through the interface and causing the crystalline precipitation was considered, but electron microprobe studies did not detect any gradient of any of the major constituents through the haze region.

To provide additional evidence that reduction of oxides in the glass was responsible for development of the haze and, perhaps, the bubbles during bonding, several metals ( $\mathrm{B}, \mathrm{No}, \mathrm{Cr}, \mathrm{V}$ ) which could reduce the low energy oxides, notably $\mathrm{As}_{2} \mathrm{O}_{3}$, were placed in contact with 7059 glass while it was melted in argon. In each case, the haze appeared and bubbling occurred. At this point it was not clear whether the development of the haze cataIyzed the release of the gases from the glass by providing a (crystalline) nucleating site for bubble growth or whether the two processes were independent. To try to answer the question, a glass was melted at the 7059 composition except that the arsenic was left out. When a fragment of this glass was remelted on Si-Ge, no haze appeared and practically no bubbles were seen. By itself, this experiment suggested that reduction of the arsenic catalyzed. bubble growth. To confirm that removal of the arsenic was responsible for the reduction of bubble growth, a second melt was made at the 7059 composition, this time including the arsenic. When this glass was remelted on siGe, the haze layer was formed, but there was again very little bubble growth. 
However, when elther glass was ground to a fine powder, bubbles were again formed. Clearly, the melting conditions (an electric fumace and low humidity) for these two glass melts were responsible for the low bubble content on remelting. The presence or absence of arsenic is not a factor in gas release. Since neither maintaining glass in a gas-free condition prior to bonding nor modifying the glass composition to prevent gas release seemed practical, the altemative of inhibiting the reaction between Si-Ge and the glass was explored. In work with thin-sheet bonded thermopiles, it was found that an oxide layer provided an excellent deterrent to the reaction. oxides thermally grown in oxygen atmospheres were the most convenient. It was aIso observed that the reaction was only delayed by the presence of an oxide layer. Apparently, once the oxide was dissolved by the glass, the reaction could take place. To be effective, the layer had to be thick enough to survive the bonding cycle.

The most effective deterrent to the reaction releasing the gas from solution was reduction of the bonding temperature. As noted above, bubbles began to appear in 7059 at temperatures between 900 and $950^{\circ} \mathrm{C}$. Maintaining the bonding temperature below $900^{\circ} \mathrm{C}$ resulted in very few bubbles.

\section{A.2. CONCLUSIONS ON VOID PRODUCTION}

The conclusions from this work are: (1) bubbles are produced by release of dissolved gases from the glass; (2) these gases can be removed from glass by vacuum melting, but are reabsorbed from the atmosphere when the glass is ground to a frit form; (3) reaction of arsenic in the glass with the Si-Ge produces the haze layer, but the haze layer is not necessary for release of dissolved gases; (4) the development of bubbles can be controlled by slowing the reaction between the glass and Si-Ge through introduction of a barrier layer and by lowering the bonding temperature. 


\section{ACKNNOWIEDGMENTS}

A task of this magnitude could not have been accomplished without the cooperation and assistance of many people. We would particularly Iike to thank Mr. C. D. Tuthill who, with Ms. A. R. Hawk and F. A. Philgreen (3621-4), carried out most of the thermopile fabrication. Many of their Ideas for handling materials, assembly, and hot-pressing have been incorporated into the production process. We would also like to thank Mr. J. A. Gilbert (5846) who performed the initial hot-pressing studies and $\mathrm{Mr} . \mathrm{R}$. J. Eagan (5846) who, with G. J. Jones (2334), provided insight into the glassSiGe reactions. We are indebted to the analysts in Department 5820 who, under the direction of J. C. Russell, provided essential information on the chemistry of the materials used in this study. We would also like to acknowledge the efforts of the Tubes Section (3621-3) who helped to develop the screen printing process for glass slurry deposition and those of R. T. Sparks (3613) who designed equipment and conducted the electrical characterization of the thermopile assemblies. 


\section{DISTRTBUTION:}

Generel Electric Company (2)

Neutron Devices Department

P.O. Box 11508

St. Petersburg, Florida 33733

Attn: A. Kuntz

$\begin{array}{ll}2300 & \text { I. D. Smith } \\ 2330 & \text { J. P. Shoup } \\ 2334 & \text { M. K. Parsons } \\ 3600 & \text { C. F. Bild } \\ 3620 & \text { R. S. Wilson } \\ 3621 & \text { D. A. Watt } \\ 3621-4 & \text { R. D. Snidow } \\ 3622 & \text { T. P. Conlon } \\ 3622-1 & \text { J. Matsko (5) } \\ 5000 & \text { A. Narath } \\ 5800 & \text { Attn: 5100, 5200, 5600, 5700 } \\ & \text { L. M. Berry } \\ 5840 & \text { Attn: 5810, 5820, 5830 } \\ & \text { D. M. Schuster } \\ 5846 & \text { Attn: 5842, 5844, 5847 } \\ 3141 & \text { E. K. Beauchamp (10) } \\ 3151 & \text { Technical Iibrary (5) } \\ 8266 & \text { Technical Writing (3) } \\ & \text { For A.E/TIC (Public Release) } \\ & \text { Iibrary (2) }\end{array}$

